\title{
Water exchange between the inner and outer archipelago areas of the Finnish Archipelago Sea in the Baltic Sea
}

\author{
Elina Miettunen ${ }^{1}\left[\right.$ : Laura Tuomi ${ }^{2} \cdot$ Kai Myrberg $^{1,3}$
}

Received: 30 March 2020 / Accepted: 3 September 2020 / Published online: 26 September 2020

(C) The Author(s) 2020

\begin{abstract}
We studied the water age and transport of passive tracers in the Archipelago Sea, Baltic Sea, using the COHERENS 3D hydrodynamic model and the OpenDrift Lagrangian particle model. The mean water age, which was calculated with COHERENS over a period of 6 years, varied between 1 and 3 months in the outer archipelago and between 3 and 6 months in the middle archipelago. The water age was highest in the inner archipelago, up to 7 months. As the density stratification is weak in large parts of this area, except for the seasonal thermocline, significant differences in the water age between the surface and bottom layers were seen only in the river mouths and in the deep channels of the middle archipelago. The Lagrangian particle simulations showed that the middle archipelago is more open towards the north than south. From the northern boundary, the Bothnian Sea, the largest transport to the middle archipelago occurred with NW winds. Due to the geometry and density of the islands in the area, the prevailing wind direction, $\mathrm{SW}$, alone is not optimal for transporting tracer particles to the middle archipelago. From the southern boundary, the Baltic Proper, transport to the middle archipelago occurred mainly with SE winds and during events when the wind direction shifted from SW to SE or vice versa. The transport further into the inner archipelago was limited to only a few cases, indicating that the inner archipelago is fairly sheltered from transport from the outer archipelago.
\end{abstract}

Keywords Baltic Sea $\cdot$ Coastal archipelago $\cdot$ High-resolution 3D modelling $\cdot$ Lagrangian tracers $\cdot$ Water age

\section{Introduction}

The present and future environmental state of marine areas is a topical issue. In particular, the coastal shallow seas, such as the Baltic Sea, are subject to enhanced anthropogenic pressures, and sheltered archipelago areas, with strongly limited water exchange with the open ocean, are extremely vulnerable to loads of nutrients or toxic substances.

Our research area, the Archipelago Sea (Fig. 1) in the Baltic Sea, has thousands of small islands and islets. The mean depth of the area is only $19 \mathrm{~m}$, but the channels that cross the area are partly deeper than $50 \mathrm{~m}$. The geometry of the Archipelago Sea

Responsible Editor: Eric Deleersnijder

Elina Miettunen

elina.miettunen@ymparisto.fi

1 Marine Research Centre, Finnish Environment Institute, Helsinki, Finland

2 Marine Research, Finnish Meteorological Institute, Helsinki, Finland

3 Marine Research Institute, Klaipeda University, Klaipeda, Lithuania is complicated. Shallow and narrow channels and clusters of islands restrict the connections between the various sub-basins. For the EU Water Framework Directive (WFD), the area has been divided into sub-basins that represent the outer archipelago, the middle archipelago and the inner archipelago (Fig. 1). The inner archipelago is the most sheltered domain with limited connections to the middle archipelago and further to the outer archipelago. Additionally, the inner archipelago is the area that first receives the riverine input from the rivers that flow into the Archipelago Sea.

The meteorological conditions in this area are variable. The most common wind direction in this area is southwest, with a significant contribution from northwest winds. The highest winds are typically from the southwest. This, together with the geometry of the archipelago and surplus of fresh water from the Gulf of Bothnia, favours north-south transport through the Archipelago Sea as shown by, for example, Tuomi et al. (2018). The surface salinity in this area varies from $4 \mathrm{~g} / \mathrm{kg}$ in the inner archipelago to $6 \mathrm{~g} / \mathrm{kg}$ in the outer archipelago. In shallow areas, there is no salinity stratification, or it is weak, as the bottom salinity is on average only $0.1-$ $0.2 \mathrm{~g} / \mathrm{kg}$ higher than the surface salinity. However, in some of the deeper channels, the bottom salinity can be higher than 


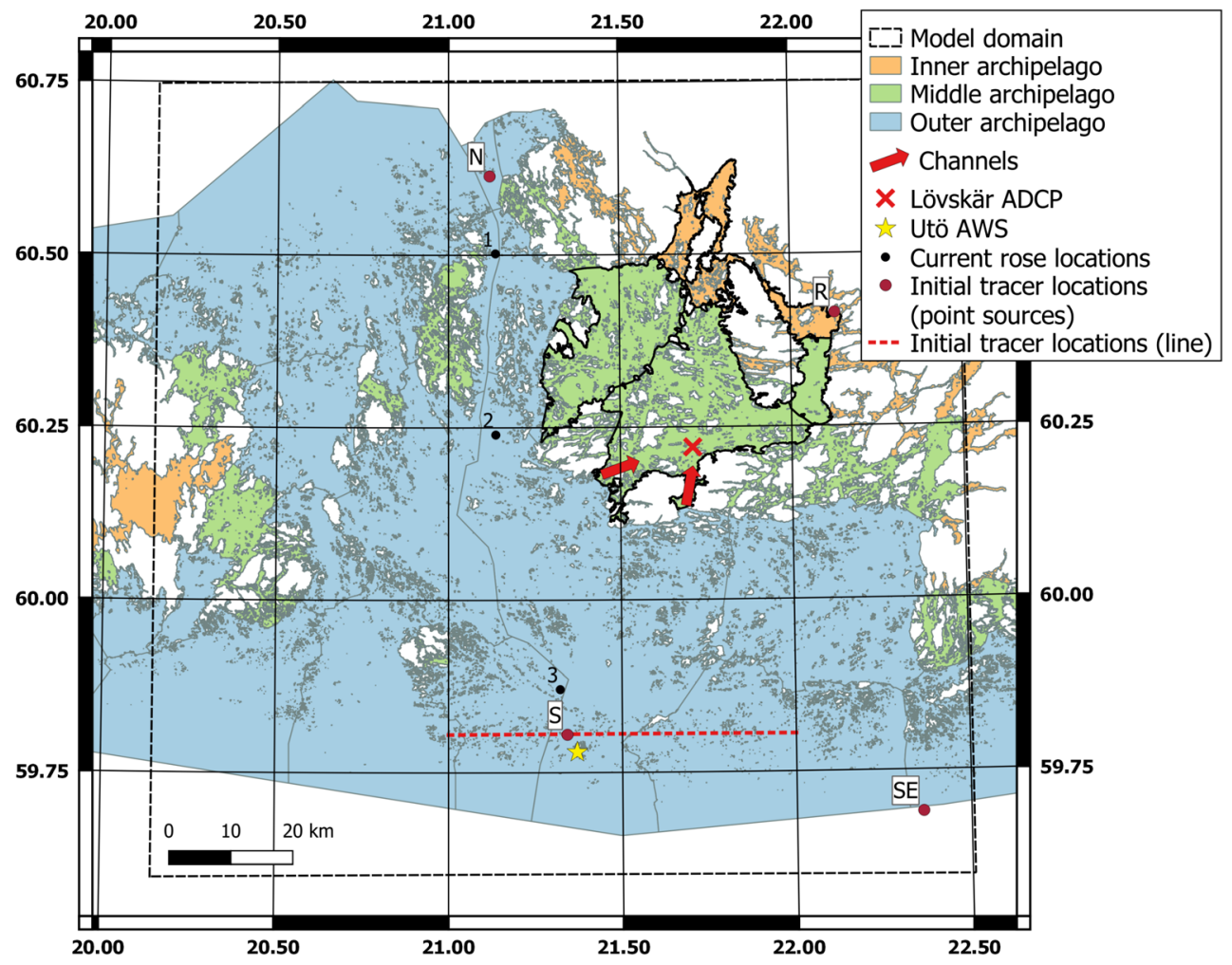

Fig. 1 The geographic division of the Archipelago Sea into the inner, middle and outer archipelago, indicated by orange, green and blue colours, respectively. Here, when talking about the middle and inner archipelagos, we refer to the green and orange areas outlined with black border lines. The yellow star indicates the location of the Utö automatic weather station (AWS), and the red cross indicates the location of the Lövskär crossing. The red arrows show the approximate locations of the western and southern channels leading to Lövskär. The red dots and the

that. For example, in a monitoring station near Utö Island in the southern part of the Archipelago Sea, the measured bottom layer salinities have ranged from 6.4 to $8.5 \mathrm{~g} / \mathrm{kg}$ (Suominen et al. 2010). The seasonal thermocline starts to develop in spring, reaching depths between 10 and $20 \mathrm{~m}$. In the shallow areas, the whole water layer warms during the summer, and stratification ceases to exist. In autumn, the thermocline is eroded by cooling and wind-induced mixing. The current speeds in the outer archipelago are higher than those in the middle or inner archipelago (Tuomi et al. 2018). However, in certain conditions, stronger currents can occur also in the channels of the middle archipelago. For example, Kanarik et al. (2018) showed that high current speeds, up to $0.4 \mathrm{~ms}^{-1}$, are possible in the middle archipelago. Their study concentrated on current measurements at the Lövskär crossing (location shown in Fig. 1). They also found that such high current speeds in this area are rare and limited to certain high wind events from specific directions, namely SE and NW.

As the Archipelago Sea is a heavily eutrophied area and many of the sub-basins in the middle and inner archipelago are in poor environmental health, a need has arisen to find tools for estimating the effects of different nutrient reduction dashed red line indicate the tracer source locations in the Lagrangian particle simulations presented in Sections 4 and 5. The black dots indicate the locations of the current roses presented in Section 4. The dashed line indicates the boundary of the high-resolution model domain. (The source for the shapefile of water bodies: Finnish Environment Institute and Centers for Economic Development, Transport and the Environment)

scenarios on the state of the coastal sea. For this purpose, Lignell et al. (2018) developed the Finnish coastal nutrient load model (FICOS). FICOS simulates nitrogen and phosphorus dynamics based on the growth and decay of algae as well as input nutrients from external sources. The model domain is divided into sub-basins of varying shapes and sizes, and the current model version has two layers in the vertical direction. The temperature and current fields used as input data have been pre-calculated with 3D hydrodynamic models.

The first results from FICOS have indicated that the inner archipelago areas, which are closest to the mainland, are significantly affected by the nutrient loads entering from the number of rivers in the area. The outer archipelago, on the other hand, is sensitive to the nutrient loading coming into the area from the Baltic Proper, located to the south of the Archipelago Sea, and from the Gulf of Bothnia, located to the north of the area. However, these first results left many open questions on the connectivity of the different areas of the Archipelago Sea, especially because of the relatively coarse resolution of the model simulation. To deepen the analysis, it is important to study the water exchange between the inner, middle and outer archipelago areas and the adjacent basins, 
Baltic Proper and the Bothnian Sea, in detail, using high spatial resolution.

One way to estimate the water exchange processes in an area is to model the water age. The concept of water age was first introduced by Bolin and Rodhe (1973). Later, Delhez et al. (1999) and Deleersnijder et al. (2001) presented a general theory of seawater age and described its use in marine modelling. The age of a water parcel is defined as the time that has elapsed since the water parcel left the area where its age is defined to be zero (Delhez et al. 1999). The general theory of seawater age (Deleersnijder et al. 2001) regards seawater as a mixture of several constituents: pure water, dissolved salts, pollutants, etc. However, because the major constituent of seawater is pure water, which is not produced or destroyed, the seawater age can be approximated with the age concentration of pure water. For example, Andrejev et al. (2004), Meier (2005) and Myrberg and Andrejev (2006) have used this approximation to estimate the water renewal in the Baltic Sea and its sub-basins. In addition to these studies, Meier (2007) studied the large-scale circulation in the Baltic Sea by marking various water masses with passive tracers and modelling the associated water ages.

When using this concept, the water age is always compared with the source of the zero-aged water, whether it is an open boundary, river discharge or point source. Meier (2005), for example, estimated that the maximum water age in the Gulf of Finland was 8.3 years when compared with the water age at the open boundary at Kattegat. Andrejev et al. (2004) estimated that the water age in the Gulf of Finland varied from less than 1 month in the western part to up to 2 years in the central eastern part when compared with the open boundary at the entrance of the Gulf of Finland. Myrberg and Andrejev (2006) estimated that the water age in the Bothnian Sea was 5-6.5 years when compared with the Northern Baltic Proper. Of these previous studies of water age in the Baltic Sea, Meier (2005) and Myrberg and Andrejev (2006) also included the Archipelago Sea. However, the horizontal resolution of these models was too coarse to solve the fine-scale characteristics of the area. Engqvist et al. (2006) were the first to estimate the water age in a coastal area of the Baltic Sea with a sufficiently high resolution, 0.1 nautical miles. They studied the water exchange in Öregrundsgrepen Bay, a small embayment on the Swedish coast, and found that with zero-aged water coming from two rivers and from the open boundary, the average water age in the area was less than approximately 3 weeks.

Although the mean water age provides important knowledge of the water retention time in different areas, it cannot be used to directly describe connectivity between sub-basins. Connectivity can be studied, for example, by extending the theory of water age to account for partial water ages that keep track of the subregions the water parcels have visited (Mouchet et al. 2016) or by using Lagrangian particle tracking models (e.g. Braunschweig et al. 2003). In this study, we use the latter method. The Lagrangian particle models introduce a set of passive particles of which trajectories are calculated based on pre-calculated velocity fields. Such simulations can then be used to study sea water pathways in general and to track the transport of various substances and objects. For a more comprehensive description of Lagrangian ocean analysis, see Van Sebille et al. (2018).

In the Baltic Sea, Lagrangian particle simulations have been used in various water age and transport studies, e.g. by Döös et al. (2004), Jönsson et al. (2004), Engqvist et al. (2006), Andrejev et al. (2011) and Viikmäe and Soomere (2018). Only one of these previous studies, namely, Engqvist et al. (2006), focused on a coastal area. In addition to the water age simulations described above, they used Lagrangian particle simulations and found that the time that individual particles stayed in the area varied from approximately 10 days to over 100 days depending on the current speeds.

In our study, we utilised a relatively new Lagrangian particle tracking framework, OpenDrift (Dagestad et al. 2018), which is open source software. In addition to a passive tracer module, OpenDrift includes several specific modules such as oil drift and pelagic egg modules. OpenDrift has been used in several studies to simulate, for example, the pathways of surface drifters (Dagestad and Röhrs 2019; Stanev et al. 2019), oil spills (Jones et al. 2016), marine litter (Gutow et al. 2018) and planktonic eggs and larvae (Kvile et al. 2018).

The main aim of this study is to evaluate the hydrodynamic interactions between the outer, middle and inner archipelagos in the Archipelago Sea. This paper is structured as follows. The modelling tools and the data they use are introduced in Section 2. Section 3 then describes the water age simulation setup and presents the results of the simulated water age. Sections 4 and 5 describe the Lagrangian tracer simulation setups and discuss the transports in the archipelago under different wind conditions. Finally, the paper ends with a summary and conclusions.

\section{Modelling}

\subsection{Hydrodynamic modelling}

In this study, we used the three-dimensional hydrodynamic model COHERENS version 2.9 (Luyten 2013) to simulate the hydrography, currents and water age in the Archipelago Sea. We used a one-way nested approach: a coarse resolution Baltic Sea setup provides pre-calculated boundary conditions for a fine-grid Archipelago Sea setup (Fig. 2). The entire Baltic Sea setup has a horizontal resolution of 2 nautical miles with 80 vertical layers, while the nested Archipelago Sea setup has a horizontal resolution of 0.25 nautical miles with 40 vertical layers. The vertical coordinate system in 
Fig. 2 Left: Domain and bathymetry of the Baltic Sea model. The red box indicates the location of the nested highresolution grid. Right: Domain and bathymetry of the highresolution Archipelago Sea model

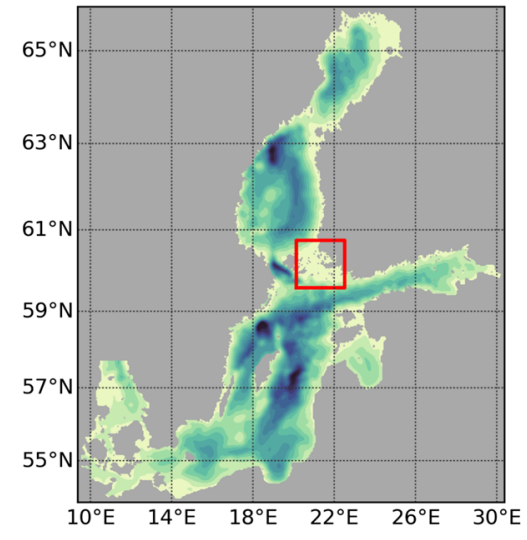

COHERENS was modified by $\gamma$-stretching introduced by Siddorn and Furner (2013). The $\sigma$-coordinates, which are used in COHERENS by default, were used in grid points with depths less than $80 \mathrm{~m}$ in the Baltic Sea setup and $40 \mathrm{~m}$ in the Archipelago Sea setup. $\gamma$-Stretching was then applied to the vertical coordinates in the deeper grid points to set the surface and bottom layer thicknesses to $1 \mathrm{~m}$ at maximum.

The bathymetry of the Baltic Sea setup is based on the IOW (the Leibniz Institute for Baltic Sea Research, Warnemünde) ocean bottom topography (Seifert et al. 2001). The bathymetry for the high-resolution Archipelago Sea setup has been compiled from bathymetric data available in coastal nautical charts of the Finnish Transport Agency and modified based on the VELMU (Finnish Inventory Program for the Marine Environment) bathymetry model (Finnish Environment Institute).

For horizontal diffusion, a Smagorinsky scheme (Smagorinsky 1963) was used in momentum equations. As the horizontal resolution of the model is relatively high, no horizontal diffusion was used for scalars. For vertical mixing, the $\mathrm{k}-\varepsilon$ parameterisation was used. A more detailed description of the configuration is given in Tuomi et al. (2018).

\subsubsection{Initial and boundary conditions}

The initial temperature and salinity fields for both setups were compiled from measurement data from the Baltic Environment Database (BED) using DAS software (Data Assimilation System; Sokolov et al. 1997). The meteorological forcing was obtained from the HIRLAM (High-Resolution Limited Area Model) numerical weather prediction system (HIRLAM-B 2016) of the Finnish Meteorological Institute (FMI), which covers north-western Europe. HIRLAM had a horizontal resolution of $0.15^{\circ}$ until 6 March 2012 and $0.068^{\circ}$ after 6 March 2012. Forcing data were gathered from daily forecast runs using the highest temporal resolution available in the model archive, which varied between 1 and $6 \mathrm{~h}$.

The Baltic Sea setup has an open boundary at northern Kattegat. For the temperature and salinity profiles at the open boundary, we used model data from Copernicus Marine Environment Monitoring Service products (http://marine. copernicus.eu/). For the sea level height at the open boundary, we used measurement data obtained from the Swedish Meteorological and Hydrological Institute (SMHI).

There are 29 major Baltic rivers included in the Baltic Sea setup. For these rivers, we used monthly mean values of discharge based on Bergström and Carlsson (1994). There are five rivers (Paimionjoki, Aurajoki, Hirvijoki, Mynäjoki and Laajoki) inside the Archipelago Sea model domain. For these rivers, we took daily values of river discharge from the VEMALA watershed model which is an operational, national-scale nutrient loading model for Finnish watersheds (Huttunen et al. 2016).

\subsubsection{Model validation}

Tuomi et al. (2018) verified the hydrodynamic model results from 2013 to 2015 with the measured temperature and salinity profiles from the Archipelago Sea area. The comparison showed that the model simulated the seasonal temperature and salinity variations in the surface layer with good accuracy. However, the bottom temperatures in the inner archipelago were not adequately modelled, as the model resolution was not high enough to describe all the details in the bottom topography.

In this study, we utilised the current measurements from the Lövskär crossing (location shown in Fig. 1) analysed in Kanarik et al. (2018) to evaluate the accuracy of the modelled currents. The measurements were carried out with a bottommounted $300 \mathrm{kHz}$ Workhorse Sentinel acoustic Doppler current profiler (ADCP) between 18 June and 13 November 2013. The measurements ranged vertically from depths of 5 to $38 \mathrm{~m}$ at $1 \mathrm{~m}$ intervals and the time interval was $20 \mathrm{~min}$. The corresponding model grid point was 37-m deep.

The water column was stratified from the beginning of the measurement period until 23 September, and a two-layer structure was seen in the measured currents. In the surface layer, at a depth of $5 \mathrm{~m}$, the current direction was mainly 
towards southwest which is well reproduced by the model (Fig. 3a). In the lower layer, at a depth of $30 \mathrm{~m}$, the current direction was the opposite, towards the northeast (Fig. 3b). The modelled current direction, however, was more towards the north than the measured current direction. This discrepancy between the modelled and measured directions is most likely due to the geometry and topography of the channels, which cannot be fully represented in the model, as their alignment is not along the grid axes.

In the autumn, cooling of the surface layer and windinduced mixing broke down the vertical stratification between 24 September and 14 October. After that, the current direction was more uniform throughout the water column, altering between SW and NE. The modelled current directions showed similar variations (Fig. 3c, d).

Overall, the model slightly overestimates the current magnitude at depths of 5-8 $\mathrm{m}$ and 28-32 $\mathrm{m}$ (bias between 0.001 and $0.008 \mathrm{~ms}^{-1}$ ) and underestimates at depths of 9-26 m and $33-36 \mathrm{~m}$. The largest bias, ranging between -0.01 and $0.02 \mathrm{~ms}^{-1}$, was found at depths of $14-23 \mathrm{~m}$ and at $36 \mathrm{~m}$, which was the lowest layer in the model.

\subsection{Water age}

The age of a water parcel is defined as the time that has elapsed since the water parcel left the area where its age is

a
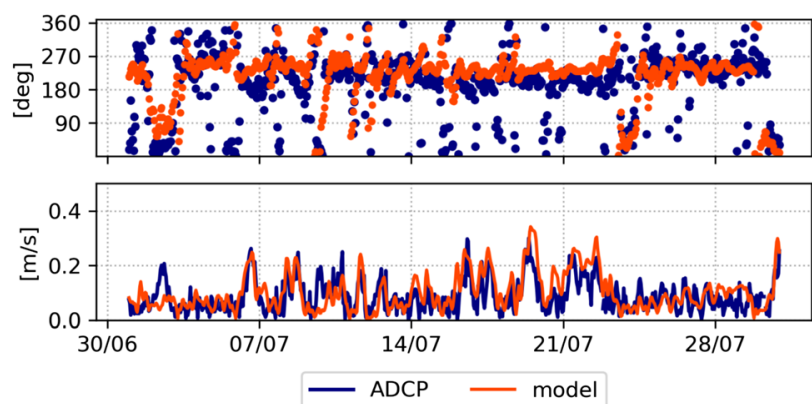

b

01 Jul - 31 Jul, $30 \mathrm{~m}$ depth
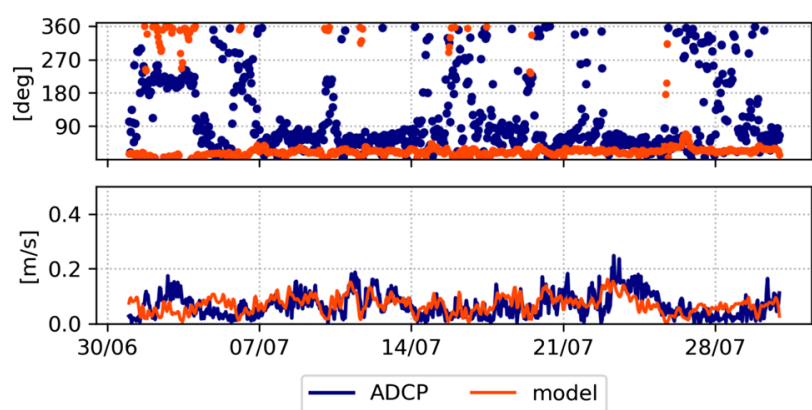

Fig. 3 Comparison between measured (blue dots and lines) and modelled (red dots and lines) current directions (upper panels) and magnitudes (lower panels) at the Lövskär crossing during 1-31 July 2013 at depths defined to be zero (Delhez et al. 1999). The general theory of seawater age (Deleersnijder et al. 2001) regards seawater as a mixture of several constituents - pure water, dissolved salts, pollutants, etc. - of which pure water is the major component. The sum of the concentrations of all constituents in a water parcel equals unity.

The mean age of each constituent is determined with two variables: concentration and age concentration. The concentration $C_{i}$ of the $i$ th constituent in a water parcel is governed by an advection-diffusion equation:

$\frac{\partial C_{i}}{\partial t}=P_{i}-D_{i}-\nabla \cdot\left(\mathbf{v} C_{i}-\mathbf{K} \cdot \nabla C_{i}\right)$

where $P_{i}$ and $D_{i}$ are the source and sink terms, respectively, $\mathbf{v}$ is the velocity and $\mathbf{K}$ is the diffusivity tensor.

The age concentration $\alpha_{i}$ of the $i$ th constituent is also governed by an advection-diffusion equation:

$\frac{\partial \alpha_{i}}{\partial t}=C_{i}+\pi_{i}-\delta_{i}-\nabla \cdot\left(\mathbf{v} \alpha_{i}-\mathbf{K} \cdot \nabla \alpha_{i}\right)$

where $\pi_{i}$ and $\delta_{i}$ are the source and sink terms, respectively. The mean age $a_{i}$ of the $i$ th constituent in the water parcel at time $t$ at location $\mathbf{x}$ is then calculated as:

$a_{i}(t, \mathbf{x})=\frac{\alpha_{i}(t, \mathbf{x})}{C_{i}(t, \mathbf{x})}$

C 23 Sep - 13 Nov, 5 m depth
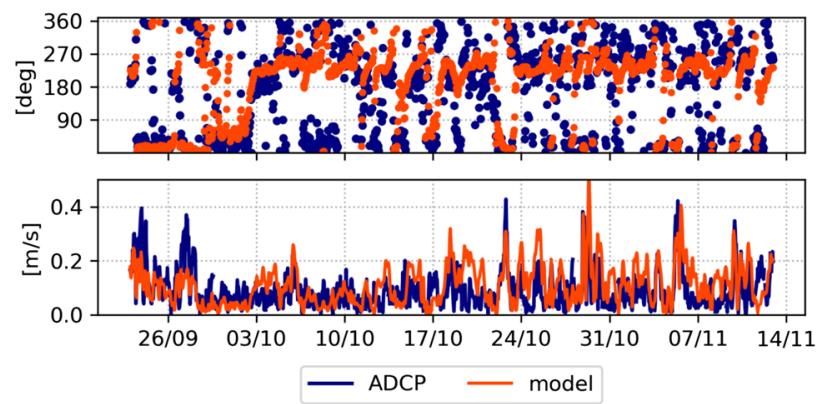

d 23 Sep - 13 Nov, 30 m depth
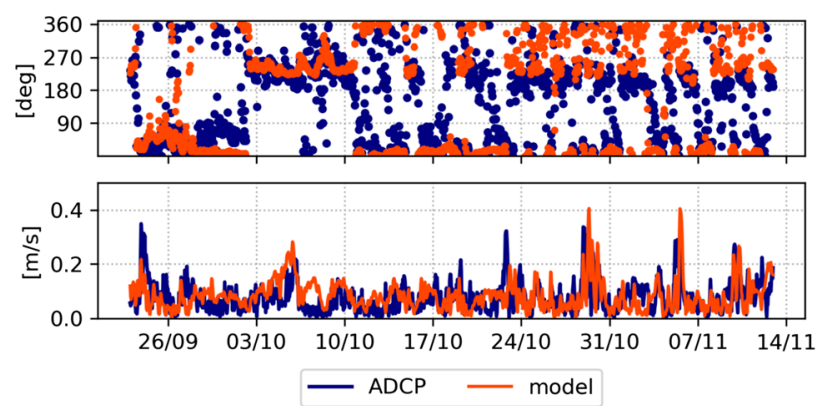

of a $5 \mathrm{~m}$ and b $30 \mathrm{~m}$ and during 23 September-13 November 2013 at depths of c $5 \mathrm{~m}$ and $\mathbf{d} 30 \mathrm{~m}$ 
However, as the sea water is mainly pure water, which is a passive constituent that is not produced or destroyed, the mean age of a water parcel can be approximated with the mean age of pure water. The age concentration of pure water, $\alpha_{0}=C_{0} a_{0}$, is almost equal to its age: $\alpha_{0} \sim a_{0}, C_{0} \rightarrow 1$. From this follows that the mean age of sea water can be approximated with the equation of age concentration of pure water:

$\frac{\partial a_{0}}{\partial t} \sim 1-\nabla \cdot\left(\mathbf{v} a_{0}-\mathbf{K} \cdot \nabla a_{0}\right)$, when $C_{0} \rightarrow 1$

This approximation has been used by, e.g. Andrejev et al. (2004), Meier (2005) and Myrberg and Andrejev (2006), to estimate the water renewal in the Baltic Sea and its sub-basins. We used this formulation in the COHERENS hydrodynamic model to study the mean water ages in the Archipelago Sea.

\subsection{OpenDrift}

To simulate the transport of particles in the Archipelago Sea, we utilised the passive tracer module of OpenDrift (Dagestad et al. 2018). The 3D current fields for these simulations were saved from the Archipelago Sea COHERENS model run with a 1-h temporal resolution. A second-order Runge-Kutta scheme was used for advection. No diffusion displacement was added to the advection of particles as the current fields have a high resolution and the flow directions are mostly restricted by the topography and geometry of the islands. Vertical turbulent mixing was not applied in the OpenDrift simulations. The time step for the particle simulations was $d t=30 \mathrm{~min}$, and the output was saved hourly. The output included the location, depth and age of each particle, as well as the current velocity and the seafloor depth at the particle locations.

OpenDrift has two options for handling the interaction with coastlines in ocean drift simulations: when the particles hit the coastline, they can be either deactivated and removed from the simulation or kept waiting at the coast until they can eventually move away as the current direction changes. As we simulated the transport of water masses or passive tracers, we used the latter option. Interaction in the open boundaries was simply such that the particles that drifted to the edge of the model domain were counted as exiting the area and removed from the simulation.

\section{Simulations of water age}

\subsection{Simulation setup}

Water age was simulated with the high-resolution Archipelago Sea setup for the years 2009-2015. As the initial condition, the water age was set to zero throughout the model domain. The boundary conditions were defined by setting the age of the inflowing water to zero at each model time step at the lateral boundaries at both the open sea boundaries and the river mouths.

We regarded the first year, 2009, as a spin-up period and calculated the mean water age over the years 2010-2015. Vertically, we averaged the results for the 1-m surface and $1-\mathrm{m}$ bottom layers to evaluate the difference in water age dynamics between the surface and bottom waters.

To study the seasonal variation in the mean water age, we also calculated seasonal means over the entire simulation period of 6 years. The periods were chosen to represent the thermal seasons of this area: January-March, which is typically the period when there is ice cover in the Archipelago Sea; April-June, which is the spring season when the surface layer starts to form; July-September, which represents the summer season with strong vertical stratification in the deep areas; and October-December, which represents the autumn with cooling and mixing of the surface layer.

\subsection{Mean water age}

The modelled water age in the surface layer was highest in the inner archipelago and lowest in the outer archipelago (Fig. 4a, the division of the archipelago is shown in Fig. 1). The mean water age in the inner archipelago was mostly less than 6 months; it was lowest at the river mouths and highest, up to or even more than 7 months, in some narrow waterways and isolated inlets. In the middle archipelago, the water age was between 3 and 6 months. In the outer archipelago, the water age was mostly less than 3 months and lowest in the open boundary areas.

The differences in the modelled water age between the surface and bottom layers were mostly small due to the weak density stratification. The age difference exceeded 1 week in only approximately $10 \%$ of the sea area in the model domain. The largest differences were in the southern part of the model domain in areas more than $30 \mathrm{~m}$ deep, in the channels leading to the middle archipelago and near the river mouths (Fig. 4b). Close to the river mouths, the water was 1-3 months older in the bottom layer than in the surface layer. Contrary to the river estuaries, the water in the deep channels in the outer and middle archipelagos was up to 1 month younger in the bottom layer than in the surface layer. In these deep areas, the seasonal thermocline leads to a two-layer structure in the currents, and the current directions between the upper and lower layers can differ, as shown in the current measurements represented in Section 2.1.2. Intrusions of more saline and colder water from the open sea occur in the deep layer, thus reducing the water age in the lower layer compared with that in the surface layer.

To study the seasonal variation, we compared the seasonal means to the mean of the 6-year period. During the winter season (January-March; Fig. 4c), the mean water age was 
Fig. 4 a Mean water age calculated over 2010-2015 (in months) in the 1-m surface layer. b Difference in the mean water age (in weeks) between the surface and bottom layers. Seasonal variation in the surface water age (seasonal mean-mean over 2010-2015; in weeks) for c JanMar, d Apr-Jun, e Jul-Sep and f Oct-Dec. Certain inlets are masked with grey colour because they are only partly represented in the model grid, which leads to possible over-estimation of the water age
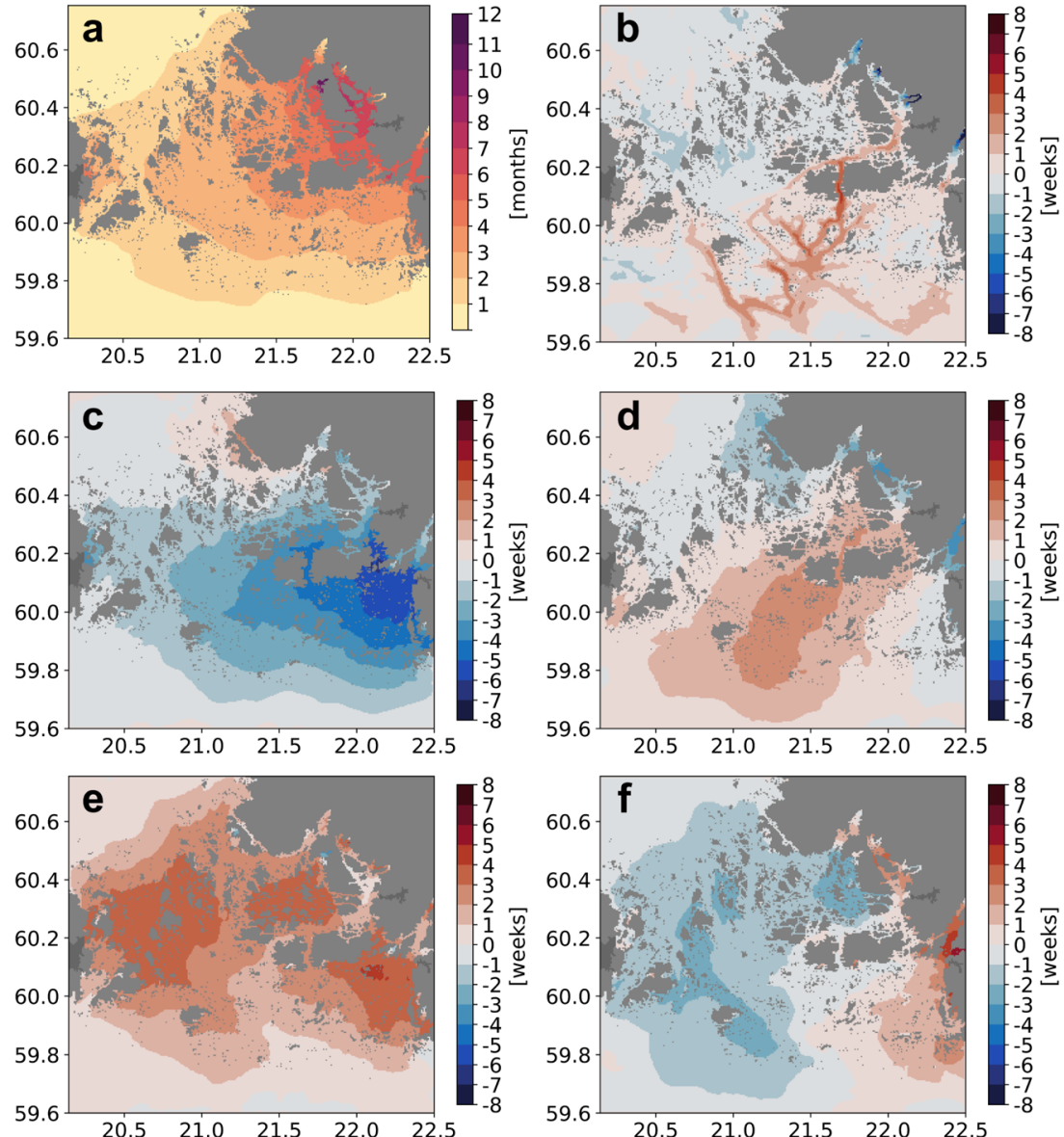

lower than the 6-year mean almost everywhere in the Archipelago Sea. Likewise, during the autumn season (October-December; Fig. 4f), the mean water age was lower than the 6-year mean almost everywhere, except for the inner archipelago and the south-eastern corner of the model domain. The current magnitudes are higher in autumn and winter, resulting in increased water exchange in the area. The spring season (April-June; Fig. 4d) showed lower water age than the 6 -year mean in the inner archipelago due to the increased river runoff. In addition, the water age was lower than the 6-year mean in the north-eastern part of the outer archipelago and higher everywhere else. During the summer season (JulySeptember; Fig. 4e), the water age was higher than the 6year mean everywhere, as the current speeds are generally lower in the summer than during other seasons.

\subsection{Inter-annual variability}

To estimate the inter-annual variability, the annual mean water ages were compared with the mean of the 6-year period (2010-2015). There were two opposite modes in the system (Fig. 5). In 2010, the mean water age in the south-eastern part of the model domain was lower than the 6-year mean and higher almost everywhere else. In 2015, the situation was the opposite: the yearly mean water age was higher than the 6 -year mean in the south-eastern part and lower elsewhere. The other years, 2011-2014, fell in between these extremes, but the years 2011 and 2014 were similar to 2010, and the years 2012 and 2013 were similar to 2015. The differences between the yearly means and the mean of the 6-year period were mainly less than 1 month, ranging between -26 and 40 days.

To evaluate the effect of the wind conditions on the year-toyear variation in the water age, we extracted the HIRLAMbased forcing, wind speed and direction, at the grid point located at the coordinates of the Utö automatic weather station (AWS; location shown in Fig. 1). This location has been shown to be representative of open sea wind conditions, with the exception of northerly winds that are blowing over the dense archipelago. Furthermore, the accuracy of the HIRLAM wind forcing has been found to be good when validated against the measured data from Utö (Tuomi et al. 2018). Considering the wind conditions evaluated over 50 years from the Utö AWS (Tuomi et al. 2018), 2015 resembled the long-term mean conditions, with prevailing SW winds. The year 2010 was quite anomalous: there was considerably more variation in the wind directions with no apparent prevailing direction and few high wind events (Fig. 5). 
Fig. 5 a Wind rose from the HIRLAM forcing data at the location of the Utö AWS (left) and the difference between the mean water age for 2010 and the mean of the 6-year period (right). b Same for 2015. The difference in mean water ages is calculated by subtracting the 2010-2015 mean from the yearly mean. Certain inlets are masked with grey colour because they are only partly represented in the model grid, which leads to possible overestimation of the water age
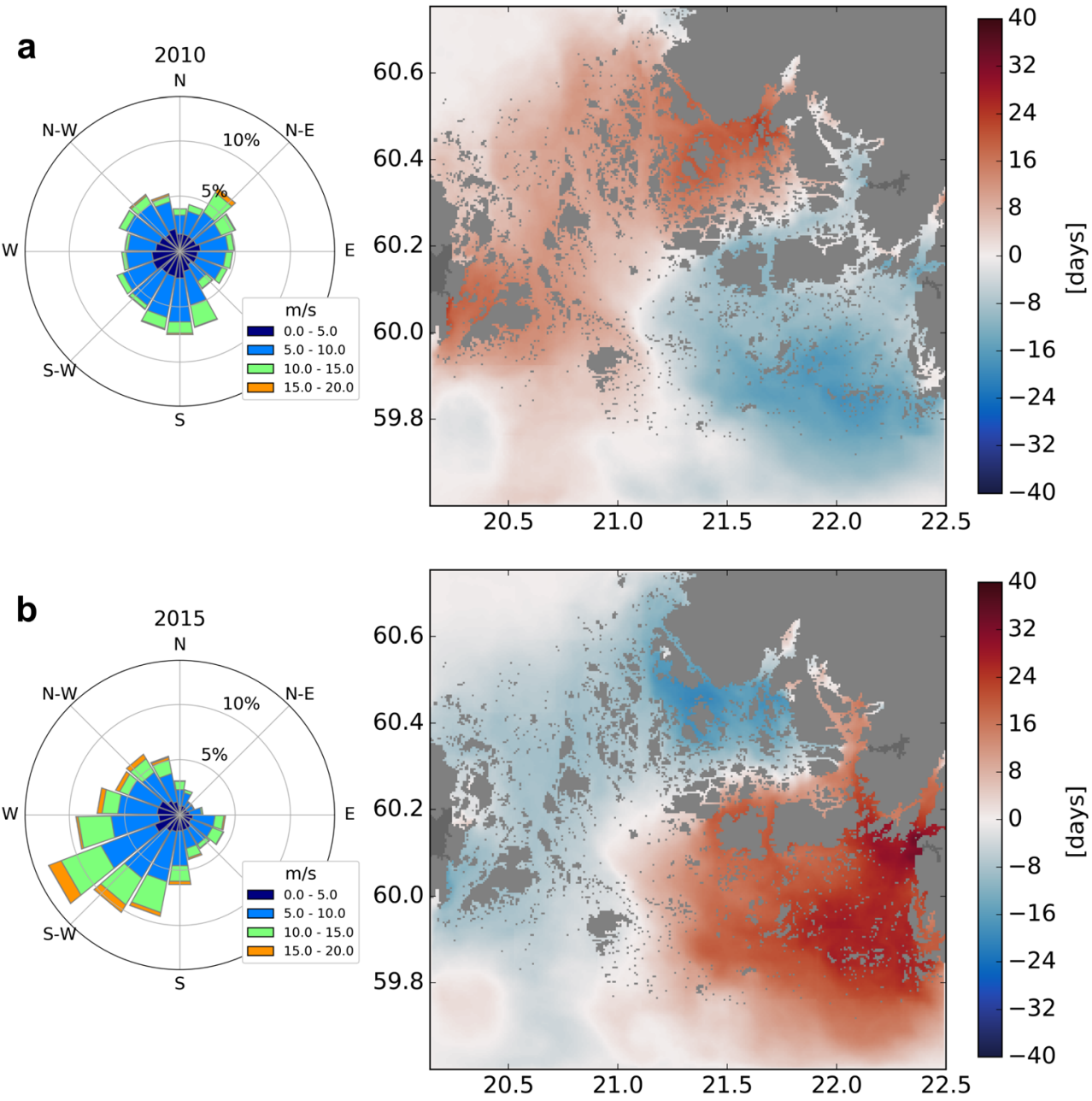

Proper (S) and the Gulf of Finland (SE). In addition, we chose one point source in the Aurajoki River estuary (point "R") to simulate the transport of tracers from the inner archipelago towards the outer archipelago. Except for point "S", these are the same locations used by Tuomi et al. (2018), who evaluated the spreading of Eulerian tracers.

We ran the simulations for each year (2013-2015) with 3month periods, Jan-Mar, Apr-Jun, Jul-Sep and Oct-Dec, to evaluate the seasonal variability in the drift of particles in addition to the inter-annual differences. In each run, particles were released to the surface layer every $12 \mathrm{~h}$ so that each time, 100 particles were distributed randomly within a $250-\mathrm{m}$ radius from the given coordinates. This resulted in 12 simulations per
Table 1 Coordinates of the point sources used in the Lagrangian particle simulations. Locations shown in Fig. 1

\begin{tabular}{llll}
\hline Run id & Lon & Lat & Description \\
\hline $\mathrm{N}$ & 21.12083 & 60.61458 & Transport from the Bothnian Sea \\
$\mathrm{S}$ & 21.34189 & 59.80524 & Transport from the Baltic Proper \\
$\mathrm{SE}$ & 22.36250 & 59.68958 & Transport from the Gulf of Finland \\
$\mathrm{R}$ & 22.12917 & 60.41458 & Transport from the Aurajoki River estuary \\
\hline
\end{tabular}


point source and $18,000-18,400$ particles per simulation (Table 2).

\subsection{Transport from open boundary areas}

For each simulation period, we calculated the percentage of particles that drifted through the outer archipelago and reached the southern (for point source "N") or northern (for point sources "S" and "SE") edge of the archipelago (Table 3). In addition, we calculated the percentage of particles that reached the middle and inner archipelago areas (outlined in Fig. 1).

The simulations showed that the prevailing wind conditions induced drift of particles mainly through the outer archipelago (Figs. 6 and 7). However, in all simulation periods, there was at least some transport to the middle archipelago. In most cases, only a small number of particles reached the inner archipelago. The drifting patterns during different periods will be discussed in more detail in the following sections.

\subsubsection{Transport from the northern edge}

The particles released at the northern point source ("N") are intended to represent transport from the Bothnian Sea to the entrance of a north-south aligned channel that leads to the central outer archipelago. Approximately $15 \mathrm{~km}$ south from point "N" (near point 1; see Fig. 1), this more open outer archipelago area expands eastward, where there are several narrow entrances to the middle archipelago.

Due to the geometry of the area, the current directions near the northern point source are mainly towards the north or south. During most of the 3-month periods, the prevailing current direction near the northern point source was northward, and $60-84 \%$ of the particles released there drifted out of the model domain through the northern boundary. The particles remaining in the model area mostly drifted southward in the outer archipelago (Fig. 6a). The least amount of particles, $38 \%$, exited at the northern boundary during AprJun 2014, when the prevailing current direction in the outer archipelago was southward. On average, it took 1-2 months for the particles to reach the southern boundary.

The southward drift was largest during Jul-Sep 2013 and Apr-Jun 2014, when 7 and 14\% of the released particles,

Table 2 The length of the Lagrangian particle simulations (days) and the number of particles per simulation $(\mathrm{N})$

\begin{tabular}{lll}
\hline Period & Days & $N$ \\
\hline Jan-Mar & 90 & 18,000 \\
Apr-Jun & 91 & 18,200 \\
Jul-Sep & 92 & 18,400 \\
Oct-Dec & 92 & 18,400 \\
\hline
\end{tabular}

respectively, reached the southern part of the model area (first column in Table 3). During these periods, the winds were mostly from NNW with speeds up to $18 \mathrm{~ms}^{-1}$, and the prevailing current direction in the outer archipelago was southward. During other periods, there was more variation in the current directions, and only up to $3 \%$ of particles reached the southern part of the Archipelago Sea. The southward drift was smallest during the periods when the prevailing wind direction was between SW and SE. Especially during Jan-Mar 2014 and Oct-Dec 2014, the prevailing current directions in the outer archipelago were towards northerly and easterly sectors, and none of the released particles reached the southern part of the Archipelago Sea.

During most periods, less than $10 \%$ of the particles entered the middle archipelago, and less than $1 \%$ reached the inner archipelago. The drift to the middle and inner archipelagos was largest during Oct-Dec 2015 (Fig. 6b) when winds were from between SW and NW with speeds up to $20 \mathrm{~ms}^{-1}$ and the current directions in the central outer archipelago (point 2) varied between NE and SE. Then, 17\% of the particles entered the middle archipelago, and 5\% reached the inner archipelago. On average, it took 1 month for the particles to reach the middle archipelago and up to 2 months to reach the inner archipelago.

\subsubsection{Transport from the southern and south-eastern edges}

The particles released at the southern point source ("S"), which is located near the entrance to the outer archipelago, are intended to represent the transport coming from the Baltic Proper to the central part of the southern outer archipelago. There was much variation in the current directions in this area, but during most simulation periods, the prevailing current direction was towards the southerly or easterly sectors. The particles from the "S" point source typically remained in the southern or central parts of the model domain, south of $60.25^{\circ} \mathrm{N}$ (Fig. 7a). A significant fraction, $40-85 \%$, of the particles exited the model area through the southern or eastern edges, and during most periods, less than $6 \%$ entered the middle archipelago.

The northward transport was significant only during periods when the dominating wind direction was between ESE and SW and there were strong northward currents in the southern outer archipelago (Jan-Mar 2014 and Oct-Dec 2014, Fig. $7 \mathrm{~b})$. During those periods, approximately $11 \%$ of the particles reached the northern edge (second column in Table 3 ), and the drift to the northern boundary took slightly over 1 month. Northward currents dominated near the southern channel leading to Lövskär, and these two periods also showed increased transport (10 and $14 \%$ of the particles) to the middle archipelago. During Jan-Mar 2015, when SW winds dominated, the drift to the northern edge was negligible (only $1 \%$ of the particles), but $6 \%$ of the particles entered the middle archipelago. 
Table 3 Main wind directions in the HIRLAM wind forcing at the location of the Utö AWS during each simulated period and the percentage of particles released from point sources "N" and "S" (locations shown in Fig. 1) that drift through the outer archipelago (southward or northward) or enter the middle and inner archipelago areas. A dash indicates no particles drifted to the area in question

\begin{tabular}{|c|c|c|c|c|c|c|c|}
\hline \multirow[t]{2}{*}{ Period } & \multirow[t]{2}{*}{$\begin{array}{l}\text { Main wind } \\
\text { directions (Utö) }\end{array}$} & \multicolumn{2}{|c|}{ Through outer archipelago } & \multicolumn{2}{|c|}{$\begin{array}{l}\text { To middle } \\
\text { archipelago }\end{array}$} & \multicolumn{2}{|c|}{$\begin{array}{l}\text { To inner } \\
\text { archipelago }\end{array}$} \\
\hline & & $\begin{array}{l}\text { Southward } \\
\text { from N }\end{array}$ & $\begin{array}{l}\text { Northward } \\
\text { from S }\end{array}$ & $\begin{array}{l}\text { From } \\
\mathrm{N}\end{array}$ & $\begin{array}{l}\text { From } \\
\mathrm{S}\end{array}$ & $\begin{array}{l}\text { From } \\
\mathrm{N}\end{array}$ & $\begin{array}{l}\text { From } \\
\mathrm{S}\end{array}$ \\
\hline Jan-Mar 2013 & SW \& NE & 1.6 & 0.2 & 5.6 & 2.0 & 0.2 & 0.1 \\
\hline Apr-Jun 2013 & SW & 0.6 & 0.0 & 8.0 & 1.7 & 0.4 & 0.0 \\
\hline Jul-Sep 2013 & NNW \& SW & 7.1 & 1.1 & 14.5 & 0.8 & 1.2 & 0.0 \\
\hline Oct-Dec 2013 & W-SW & 1.4 & 0.0 & 12.2 & 1.2 & 3.2 & 0.0 \\
\hline Jan-Mar 2014 & SSE & - & 11.5 & 2.4 & 9.7 & 0.1 & 0.3 \\
\hline Apr-Jun 2014 & NNW & 13.9 & 0.0 & 12.4 & 0.8 & 0.5 & 0.0 \\
\hline Jul-Sep 2014 & SW & 0.5 & 0.5 & 3.3 & 4.3 & 0.3 & 0.0 \\
\hline Oct-Dec 2014 & SW \& SE & - & 11.2 & 2.5 & 13.5 & 0.1 & 0.8 \\
\hline Jan-Mar 2015 & SW & 0.1 & 0.8 & 3.4 & 5.6 & 0.3 & 0.2 \\
\hline Apr-Jun 2015 & SW \& NW & 0.7 & 0.1 & 11.4 & 2.0 & 2.0 & 0.0 \\
\hline Jul-Sep 2015 & SW & 0.9 & 1.7 & 6.2 & 2.5 & 0.5 & 0.0 \\
\hline Oct-Dec 2015 & W-SW & 2.9 & 0.0 & 16.7 & 0.5 & 4.6 & 0.0 \\
\hline
\end{tabular}

Even during these three periods, transport to the inner archipelago was small, and less than $1 \%$ of the particles drifted to this area. During other periods, only $1-4 \%$ of the particles entered the middle archipelago, and less than $1 \%$ reached the northern edge, taking 1-2 months to drift to this area. These periods had a significant fraction of winds from westerly or northerly directions that did not enhance northward transport.

The particles released at the south-eastern point source ("SE") behaved similarly to those released from point "S". The particles typically stayed south of $60^{\circ} \mathrm{N}$, and those that exited the model area (64-97\% of all particles) mostly drifted out at the southern and eastern edges. The southward or southeastward transport was largest when the wind directions were between SW and NW. During the periods with southerly winds, Jan-Mar 2014 and Oct-Dec 2014, up to 4\% of the particles exited the model area at the northern edge, up to $6 \%$ reached the middle archipelago and less than $0.5 \%$ reached the inner archipelago.

\subsection{Transport from the river estuaries}

The tracer particles released in the Aurajoki River estuary (point source "R") stayed mostly in the inner and middle archipelago areas during the 3-month simulation periods: $68-$ $90 \%$ of the released particles drifted to the middle archipelago and up to $16 \%$, but typically less than $6 \%$, reached the outer archipelago. On average, it took approximately 10-20 days for the particles to reach the boundary between the inner and the middle archipelago, situated $6.5 \mathrm{~km}$ southwest from the initial location. However, as the current speeds in this area are relatively small with varying directions, many particles circulated for a relatively long time in the basin closest to the river mouth before drifting to the south. From the boundary between the inner and middle archipelago, it took 1-2 months on average for the particles to drift to the outer archipelago. In general, the 3-month simulation period was not long enough for the particles to reach the open sea areas, and less than $1 \%$ of the particles exited the model area.

\section{Transport from the Northern Baltic Proper towards the middle archipelago}

As shown in the previous section, only a small percentage of the particles released in the southern and northern parts of the model area entered the middle and inner archipelagos. The tracers from the northern point source entered the middle archipelago more often than the tracers from the southern point source.

The transport from southern open sea areas towards the middle archipelago is restricted by the location and geometry of the islands and channels. There are two narrow channels, aligned in approximately $\mathrm{W}$ and $\mathrm{S}$ directions (locations shown in Fig. 1), that enable transport to the middle archipelago from southern open sea areas. Kanarik et al. (2018) showed that in the crossing of these two channels, the Lövskär crossing (the location shown in Fig. 1), only winds from the SE and NW sectors were able to induce surface current speeds higher than $0.2 \mathrm{~ms}^{-1}$.

To study the effect of geometry and wind conditions on the transport of tracers from the southern open sea areas to the middle archipelago, we studied southerly wind events from 2013 to 2015 (excluding periods when there was ice cover in the area). This selection resulted in 42 wind events, and their duration varied between 2 and 24 days. The simulations were 
Fig. 6 Drift of particles from the northern point source, the wind roses from the HIRLAM forcing data at the locations of the Isokari and Utö AWSs and the current roses from points 1 and 2 (locations shown in Fig. 1) during a Apr-Jun 2013 and b Oct-Dec 2015. The grey lines show the trajectories of the particles, and the green and blue dots denote the initial and final positions of the particles, respectively
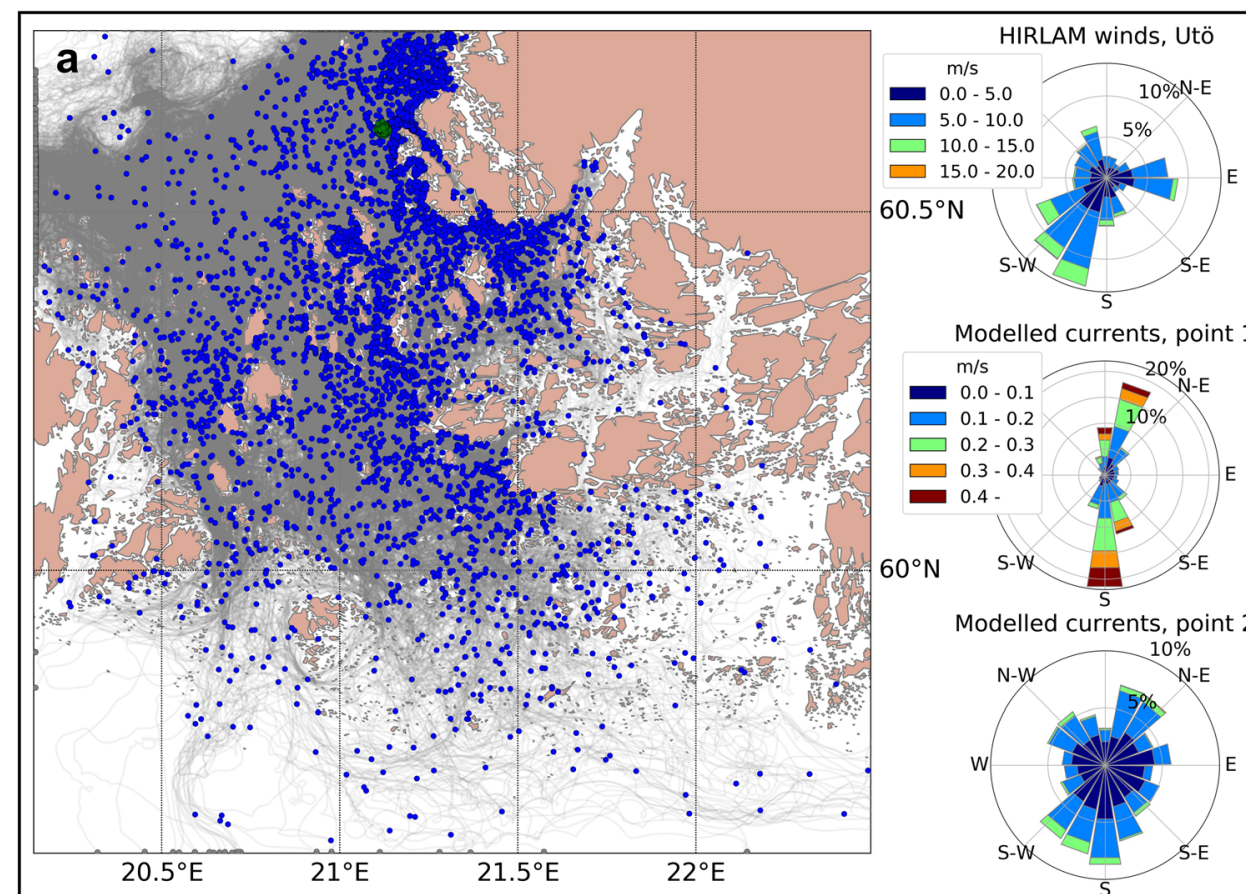

Modelled currents, point 1

$\mathrm{m} / \mathrm{s}$

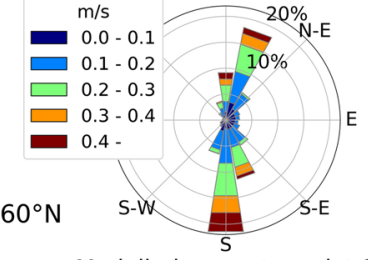

Modelled currents, point 2
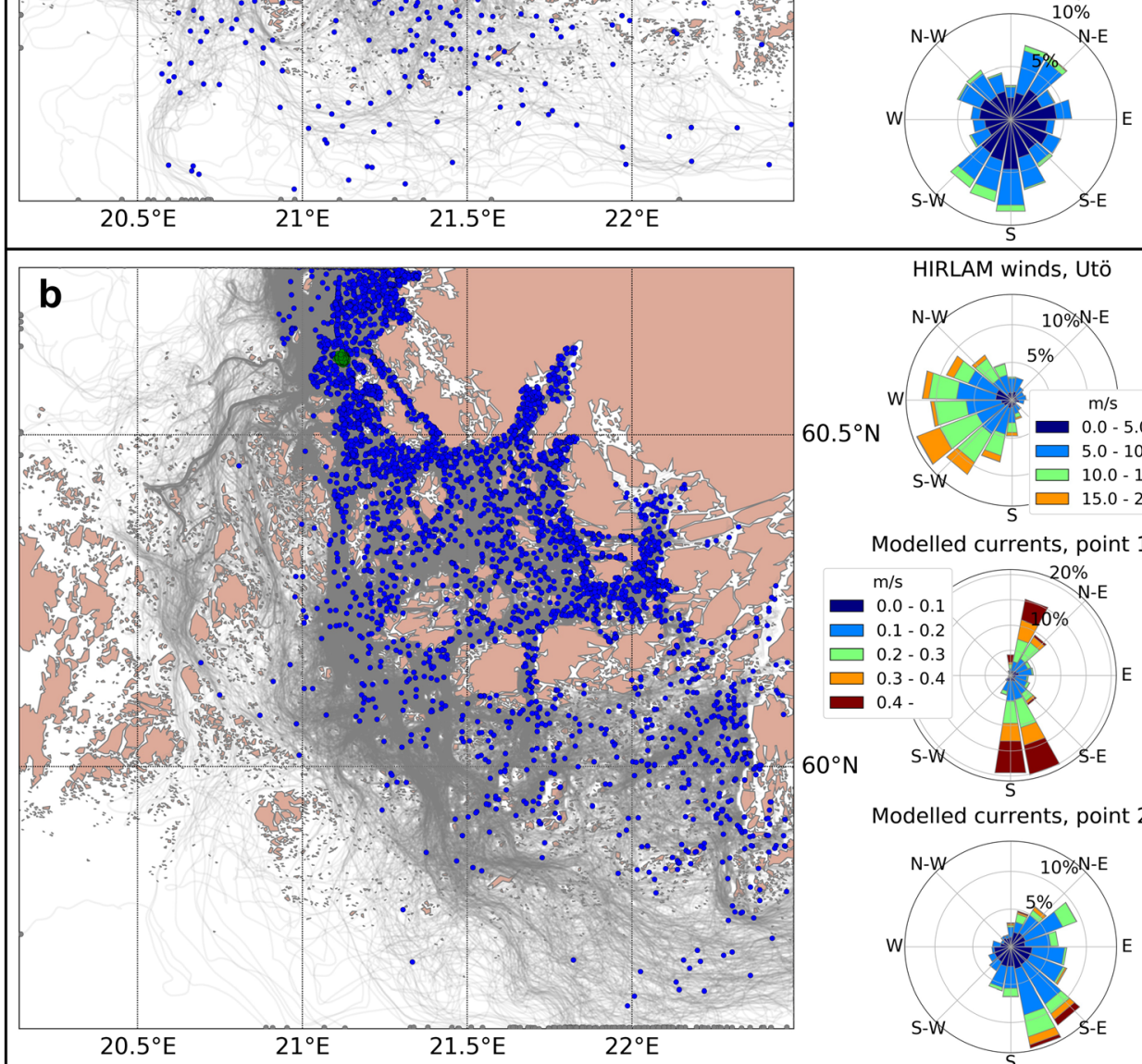

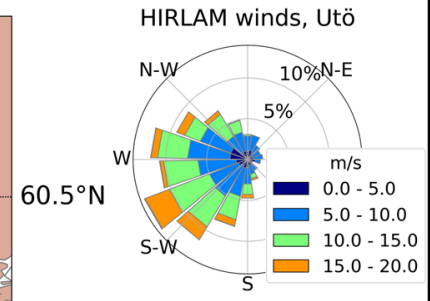

Modelled currents, point 1

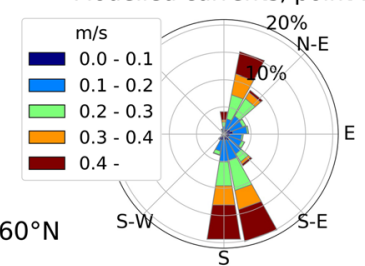

Modelled currents, point 2

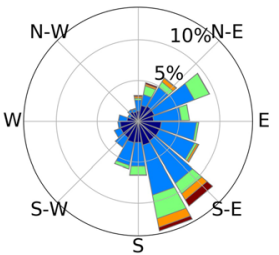

carried out by releasing $N=9381$ particles distributed evenly at $1-50 \mathrm{~m}$ depths along a $56-\mathrm{km}$-long line near the southern edge of the Archipelago Sea $\left(21^{\circ} \mathrm{E}-22^{\circ} \mathrm{E}\right.$ at $59.81^{\circ} \mathrm{N}$, location shown in Fig. 1) at the beginning of each simulation.

To evaluate the difference in the drift of particles between the upper and the lower layers, we divided the water column into a surface layer of $0-15 \mathrm{~m}$ and a lower layer from $15 \mathrm{~m}$ downwards. The division was chosen so that the upper layer represents the well-mixed surface layer in summer. For both layers, we calculated the particle densities in the original model grid at each output time step and used this to estimate the sum of particles passing through each grid point during the simulation.

Of the 42 events, 14 showed transport towards the middle archipelago through the southern or western channels (column 1 in Table 4; a more detailed list of these events is provided in Table 5). In six of these 14 events, the tracers were transported through the channels to the Lövskär crossing, and in the other 
Fig. 7 Drift of particles from the southern point source, the wind roses from the HIRLAM forcing data at the locations of the Isokari and Utö AWSs and the current roses from the Lövskär crossing and point 3 (locations shown in Fig. 1) during a Apr-Jun 2015 and b Oct-Dec 2014. The grey lines show the trajectories of the particles, and the green and blue dots denote the initial and final positions of the particles, respectively
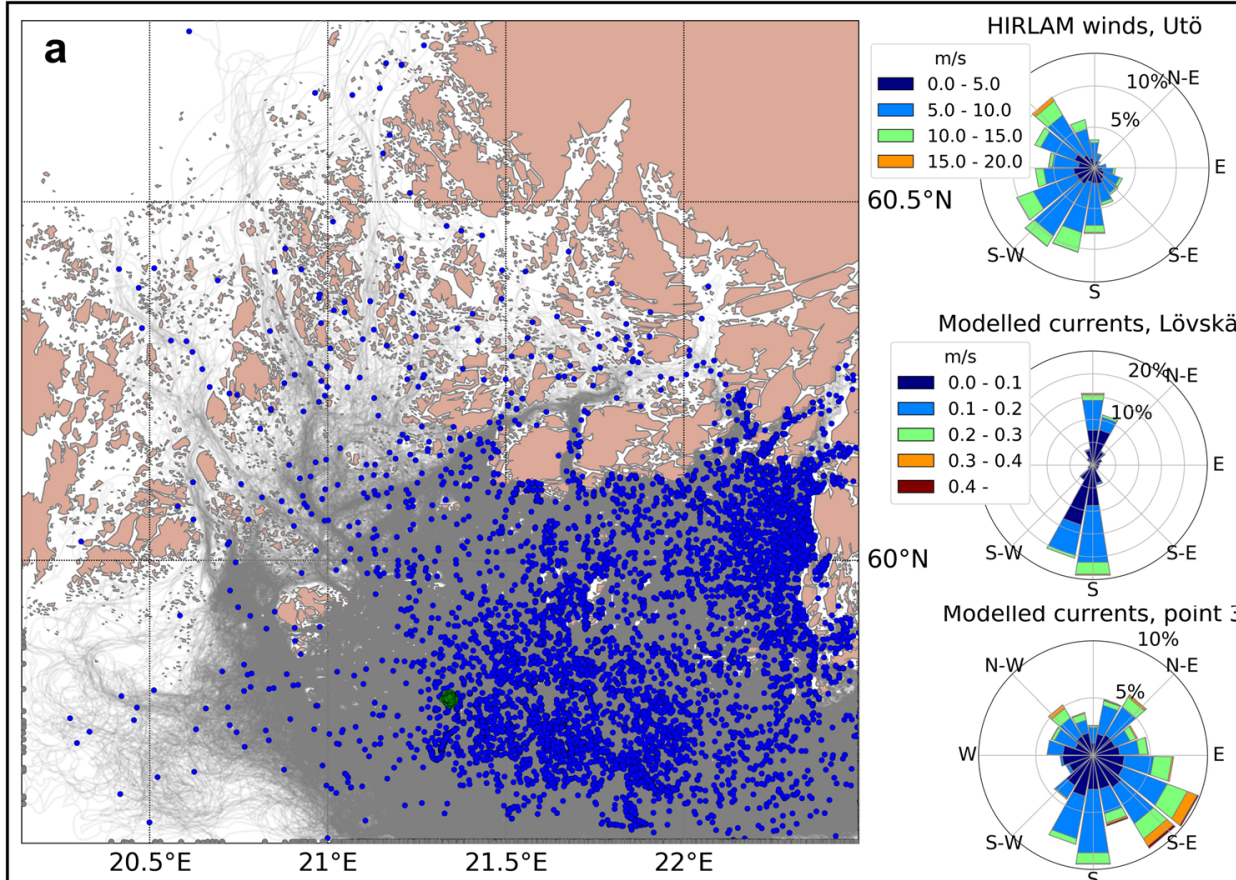

Modelled currents, Lövskär

$\mathrm{m} / \mathrm{s}$

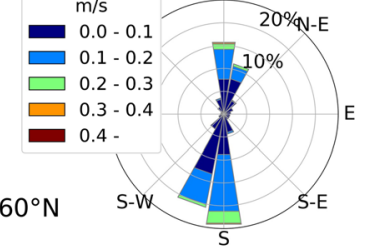

Modelled currents, point 3
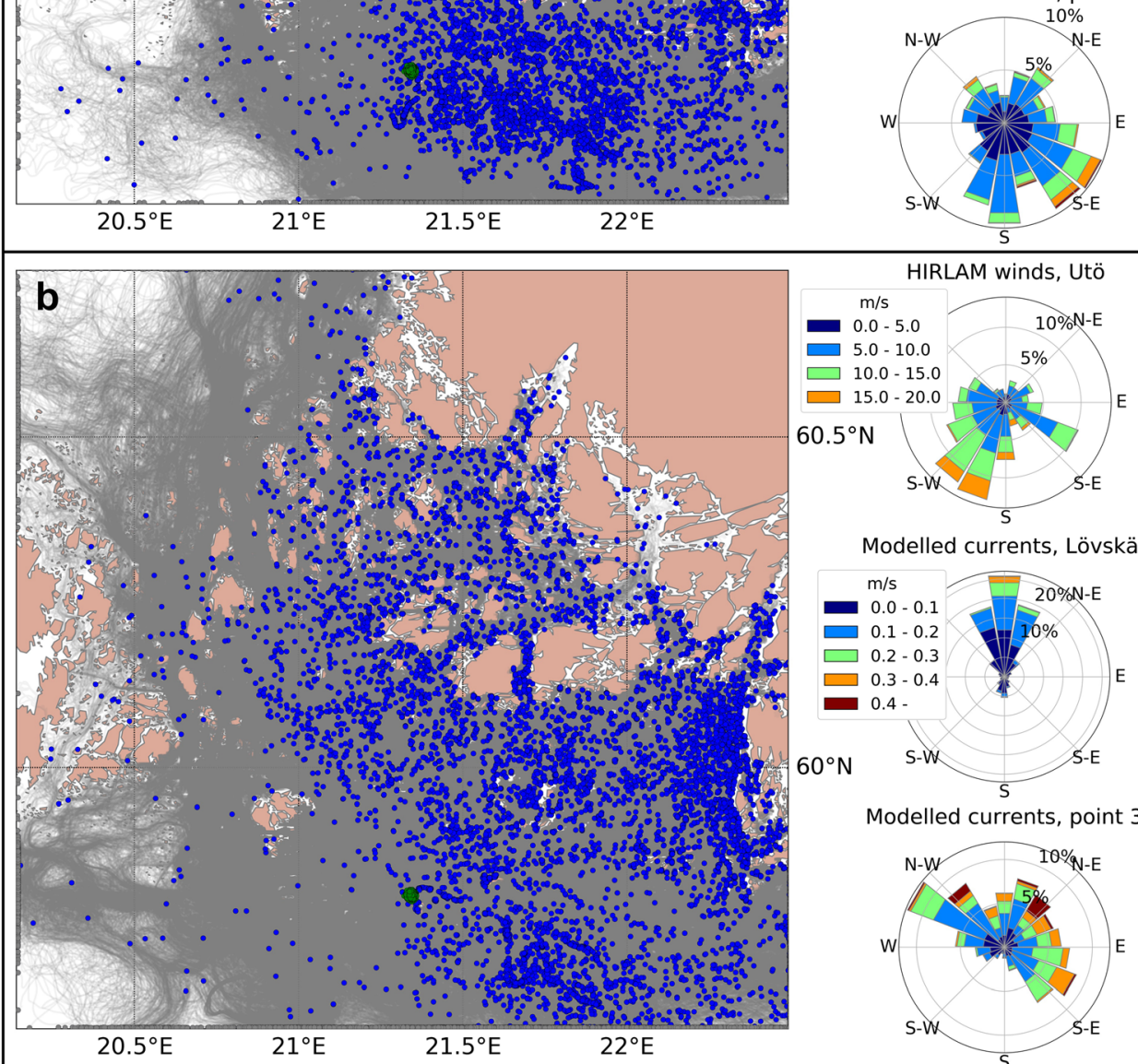

HIRLAM winds, Utö

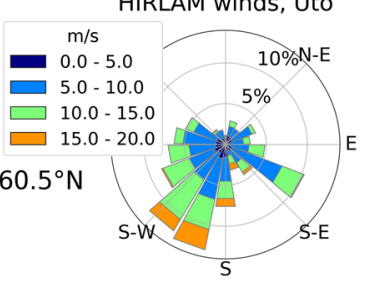

Modelled currents, Lövskär

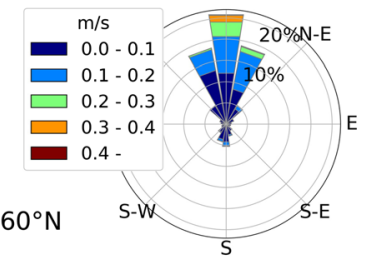

Modelled currents, point 3

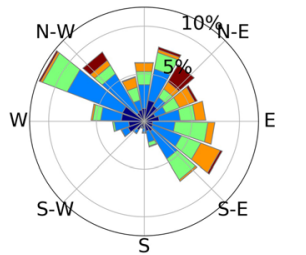

eight events, the particles only entered the channels. In addition, there were five events in which the tracers reached the entrances of one or both of the channels (column 2 in Table 4).

Of the 14 events that showed transport to the middle archipelago, there were four events with south-easterly winds, two events with south-westerly winds and eight events where the wind shifted between south-easterly and south-westerly sectors. In the two events that showed transport with the SW winds, the prevailing wind direction was SSW, close to the south-easterly sector.

The shortest period showing transport to Lövskär in the surface layer lasted only 5 days and had a prevailing wind direction from the southeast with a mean wind speed of $9.6 \mathrm{~ms}^{-1}$ and a maximum wind speed of $13.9 \mathrm{~ms}^{-1}$ (Fig. 8a). The particles were mostly transported northwest and north towards the middle archipelago and the channels leading to 
Table 4 Number and length of the events that (1) showed transport into the middle archipelago, (2) showed transport to the borders of the middle archipelago or (3) showed no transport to the middle archipelago and the mean and maximum wind speeds during the events. $n$ tot, total number of events from each wind sector; $n$, number of events

\begin{tabular}{|c|c|c|c|c|c|c|c|c|c|c|c|}
\hline \multirow{3}{*}{$\begin{array}{l}\text { Prevailing wind } \\
\text { direction }\end{array}$} & \multirow{3}{*}{ ntot } & \multicolumn{3}{|c|}{$\begin{array}{l}\text { (1) Transport into the middle } \\
\text { archipelago; } 14 \text { events }\end{array}$} & \multicolumn{3}{|c|}{$\begin{array}{l}\text { (2) Transport near the borders of the } \\
\text { middle archipelago; } 5 \text { events }\end{array}$} & \multicolumn{4}{|c|}{$\begin{array}{l}\text { (3) Other cases: no transport to the } \\
\text { middle archipelago; } 23 \text { events }\end{array}$} \\
\hline & & \multirow{2}{*}{$\begin{array}{l}\text { Length } \\
\text { (days) }\end{array}$} & \multicolumn{2}{|c|}{ Wind speed $\left(\mathrm{ms}^{-1}\right)$} & \multirow{2}{*}{$\begin{array}{l}\text { Length } \\
\text { (days) }\end{array}$} & \multicolumn{2}{|c|}{ Wind speed $\left(\mathrm{ms}^{-1}\right)$} & \multirow[t]{2}{*}{$n$} & \multirow{2}{*}{$\begin{array}{l}\text { Length } \\
\text { (days) }\end{array}$} & \multicolumn{2}{|c|}{ Wind speed $\left(\mathrm{ms}^{-1}\right)$} \\
\hline & & & Mean & $\operatorname{Max}$ & & Mean & $\operatorname{Max}$ & & & Mean & Max \\
\hline SE sector $\left(90-180^{\circ}\right)$ & 8 & $4 \quad 5-24$ & $9.3-10.4$ & $13.9-18.2$ & $0-$ & - & - & 4 & $3-9$ & $4.0-8.6$ & $8.8-11.3$ \\
\hline SW sector $\left(180-270^{\circ}\right)$ & 19 & 214 & $5.4-7.2$ & $10.4-16.5$ & $37-16$ & $11.0-13.5$ & $16.1-20.6$ & 14 & $2-12$ & $5.5-13.2$ & $8.3-20.0$ \\
\hline $\begin{array}{l}\text { Both SW and SE } \\
\text { sectors }\end{array}$ & 15 & $8 \quad 6-22$ & $5.7-13.7$ & $11.2-18.8$ & $28-9$ & $7.7-9.4$ & $14.2-15.7$ & 5 & $3-6$ & $4.1-8.5$ & $7.5-15.6$ \\
\hline
\end{tabular}

the Lövskär area. When this simulation period was extended by 7 days (not shown), more transport to the middle archipelago occurred even though the wind direction changed from SE to NW. During longer wind events, transport was also seen with lower mean wind speeds: an event with a mean wind speed of only $5.7 \mathrm{~ms}^{-1}$ showed transport to Lövskär, but the length of the event was 14 days with prevailing SE winds.

In a few cases, there were different drifting patterns in the surface layer and the lower layer. One example of this difference was a 2-week period in May 2013 that had a prevailing wind direction from the southwest with a mean wind speed of $5.4 \mathrm{~ms}^{-1}$ and a maximum wind speed of $10.4 \mathrm{~ms}^{-1}$ (Fig. 8b). The particles in the 15-m surface layer stayed in the outer archipelago and mostly drifted towards the east and southeast (Fig. 8d). In the lower layer, below $15 \mathrm{~m}$, there was also northward transport of particles to the middle archipelago along the channels (Fig. 8f). When this simulation period was extended by 7 days (not shown), the wind direction turned from SW to E and later to NE, and there was some transport towards the middle archipelago even in the surface layer. In the lower layer, more particles drifted to the middle archipelago and further towards the inner archipelago. Some of the particles that reached the middle archipelago in the lower layer were also transported vertically upwards to the 15-m surface layer.

\section{Discussion}

The analysis of the water age calculations showed that the Archipelago Sea has a relatively low water age compared with the surrounding open sea areas. This result indicates that the Archipelago Sea area is very dynamic and under constant influence of both riverine input (the inner archipelago) and
Table 5 Simulated wind events that showed some transport to the middle archipelago in the surface layer of $15 \mathrm{~m}$ or in the lower layer below that. " $x$ " indicates transport to the Lövskär area, "(x)" indicates that the tracers reached only the channels

\begin{tabular}{|c|c|c|c|c|c|c|}
\hline \multirow[t]{2}{*}{ Simulation period } & \multirow[t]{2}{*}{ Length (days) } & \multirow[t]{2}{*}{ Main wind direction } & \multicolumn{2}{|c|}{$\begin{array}{l}\text { Wind speed } \\
\left(\mathrm{ms}^{-1}\right)\end{array}$} & \multicolumn{2}{|c|}{$\begin{array}{l}\text { Transport to the middle } \\
\text { archipelago }\end{array}$} \\
\hline & & & Mean & Max & $0-15 \mathrm{~m}$ & $15 \mathrm{~m} \rightarrow$ \\
\hline $1-15.5 .2013$ & 14 & SSW & 5.4 & 10.4 & & $\mathrm{x}$ \\
\hline $14-18.9 .2013$ & 5 & SE & 9.6 & 13.9 & (x) & $(\mathrm{x})$ \\
\hline $1-9.1 .2014$ & 8 & SSE and WSW & 8.8 & 14.0 & $(\mathrm{x})$ & $(\mathrm{x})$ \\
\hline $24.1-17.2 .2014$ & 24 & SSE & 9.3 & 15.9 & $\mathrm{x}$ & $\mathrm{x}$ \\
\hline 6-20.7.2014 & 14 & E and SW & 5.7 & 11.2 & $\mathrm{x}$ & $(\mathrm{x})$ \\
\hline 2-24.8.2014 & 22 & SE and SW & 7.2 & 14.7 & $\mathrm{x}$ & $\mathrm{x}$ \\
\hline $4-13.10 .2014$ & 9 & SE and SW & 8.6 & 17.7 & $(\mathrm{x})$ & $(\mathrm{x})$ \\
\hline $21-29.10 .2014$ & 8 & SE and SW & 13.7 & 16.6 & $(\mathrm{x})$ & $(\mathrm{x})$ \\
\hline 23-29.11.2014 & 6 & SSE and SSW & 7.3 & 16.6 & $(\mathrm{x})$ & $(\mathrm{x})$ \\
\hline $15-31.1 .2015$ & 16 & SSW and ESE & 10.6 & 18.8 & $\mathrm{x}$ & $\mathrm{x}$ \\
\hline $15.2-2.3 .2015$ & 16 & $\mathrm{~S}$ and $\mathrm{SW}$ & 10.0 & 17.3 & (x) & $(\mathrm{x})$ \\
\hline $25-31.3 .2015$ & 6 & $\mathrm{SE}$ & 10.4 & 17.3 & $(\mathrm{x})$ & $(\mathrm{x})$ \\
\hline $20.5-3.6 .2015$ & 14 & SSW & 7.2 & 16.5 & $(\mathrm{x})$ & \\
\hline $13-18.9 .2015$ & 6 & SE & 9.6 & 18.2 & $\mathrm{x}$ & $(\mathrm{x})$ \\
\hline
\end{tabular}


Fig. 8 Wind speed and direction from the HIRLAM forcing data at the location of the Utö AWS during the simulation periods a 14 to 18 September 2013, and b 1 to 15 May 2013. Amount of tracer particles passing through each model grid point during the simulation in the 15-m surface layer $(\mathbf{c}, \mathbf{d})$ and in the rest of the water column $(\mathbf{e}, \mathbf{f})$ a $14-18$ Sep 2013
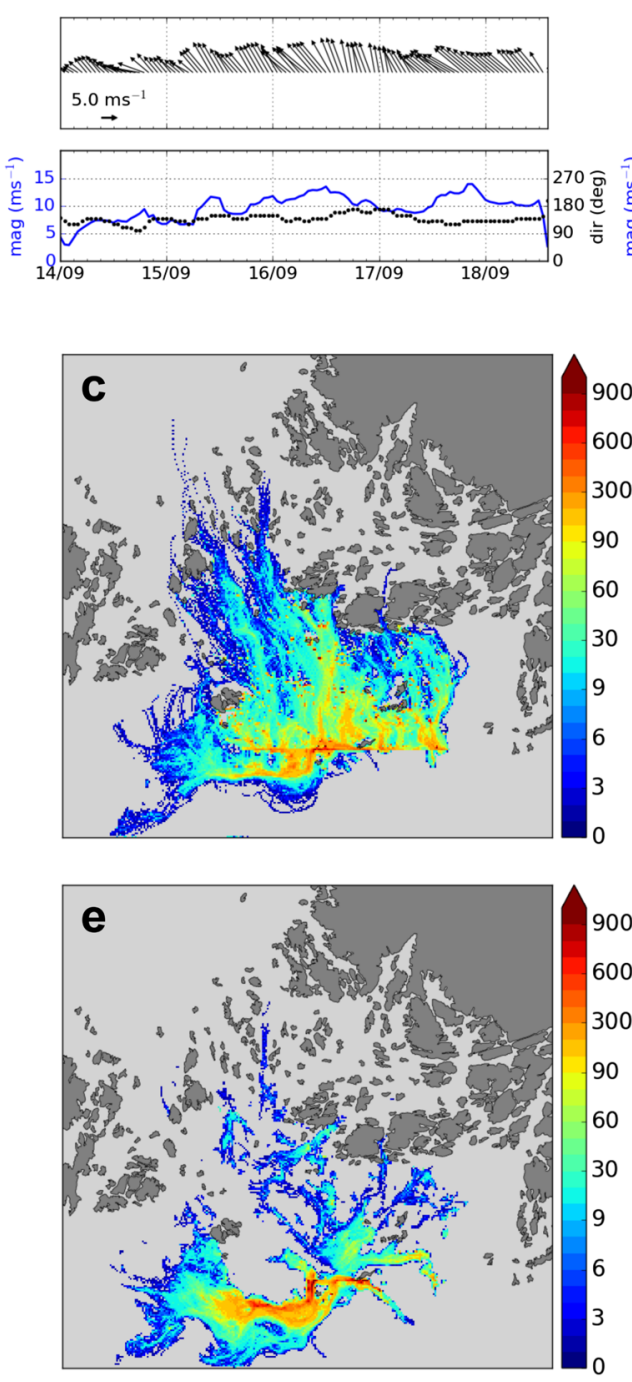

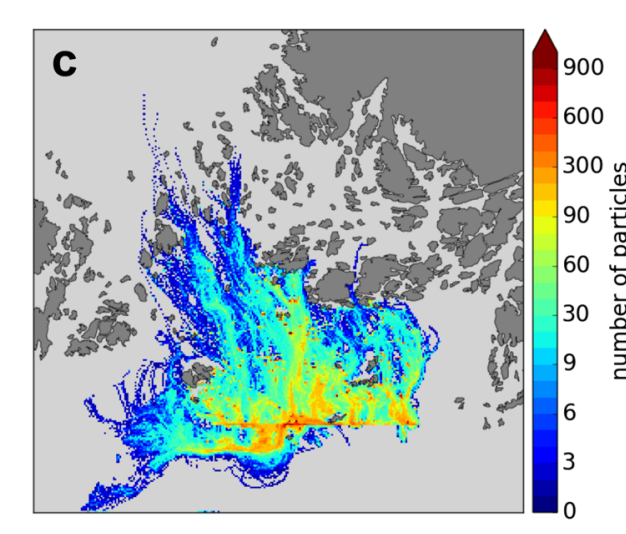

b $\quad 1$ - 15 May 2013

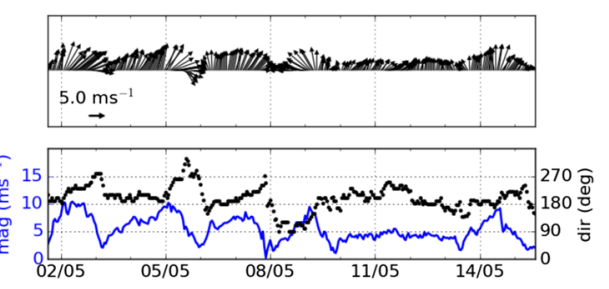

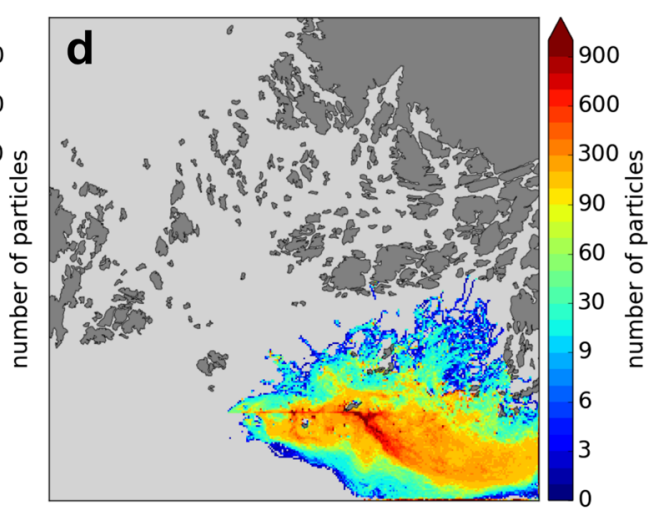

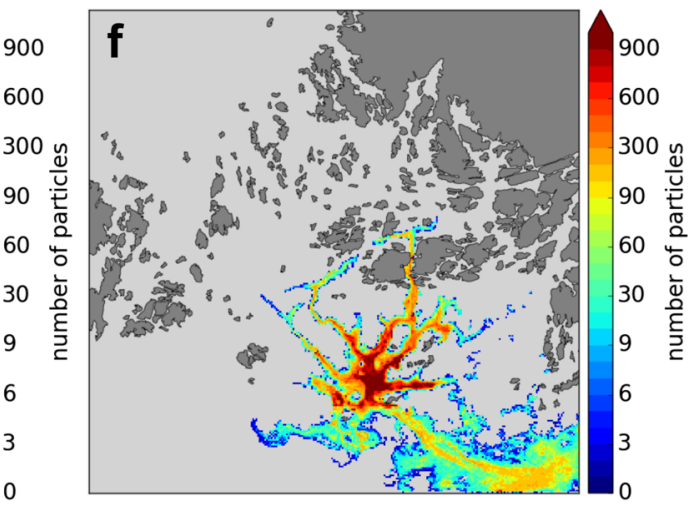

transport from the Baltic Proper and the Bothnian Sea. The difference between the mean water ages in the inner and outer archipelago was up to 7 months. During the autumn and winter seasons, when the wind and current speeds are highest, the water age was generally lower than the mean age over the 6year period. During the spring season, the increased river runoff resulted in lower water ages in the inner archipelago than the 6-year mean.

The circulation and transport of substances in the Archipelago Sea are affected by the complex geometry and clusters of small islands and islets. The prevailing wind direction, southwest, is not optimal for the transport of tracers through the Archipelago Sea. The middle and inner archipelagos are mostly sheltered from transport from the outer archipelago. The 3-month drift simulations presented in subsection 4.2 showed, however, that the middle archipelago is more open towards the north than south, as the largest amount of particles drifted to the middle archipelago from the northern boundary. The simulations presented in Section 5 also showed that the middle archipelago is relatively sheltered from the southern direction. The particles are able to enter the channels leading to the middle archipelago only if they are near the entrance when strong enough wind turns the current towards the channel. In most of the SW wind cases, the tracer particles released near the southern edge of the archipelago did not reach the channels but remained in the southern outer archipelago. South-easterly winds are more optimal for south-north transport of particles and for transport into the middle archipelago than south-westerly winds. However, due to the relatively low probability of SE winds, transport into the middle archipelago is limited to only a few situations.

In our analysis, we divided the wind events into SE (90$\left.180^{\circ}\right)$ and SW $\left(180-270^{\circ}\right)$ sectors. As the analysis from the SW sector showed, in the SW cases where there was transport to the middle archipelago, the prevailing wind direction was SSW. This result indicates that the wind directions that induce transport to the middle archipelago are between ESE and SSW. Since there is much year-to-year variability in the 
meteorological conditions, longer simulation periods are needed to more accurately determine the sector of wind directions that are optimal for transport to the middle archipelago.

In addition to wind direction, the duration and strength of the wind event also affect the transport of substances. The shortest period showing transport to the middle archipelago in the surface layer lasted for 5 days with a mean wind speed of $9.6 \mathrm{~ms}^{-1}$, whereas the lowest mean wind speed causing transport in the surface layer was $5.7 \mathrm{~ms}^{-1}$; this period lasted for 14 days. All the periods showing transport in the surface layer had maximum wind speeds higher than $11.0 \mathrm{~ms}^{-1}$. The majority of the simulated events showing surface transport to the middle archipelago occurred during autumn and winter seasons, which typically have stronger winds than spring and summer.

The length of the simulations in Section 5 was selected based on the length of the southerly wind events. Once the water mass is set into motion, it continues a while due to inertia even after the wind speed has decreased and its direction has changed. Therefore, in some cases, particles that had already drifted close enough to the channels leading to the middle archipelago entered the middle archipelago when the simulation periods were extended for an additional 7 days.

As Tuomi et al. (2018) showed, compared with the coarse resolution models $(1-2 \mathrm{nmi})$, the high resolution of the Archipelago Sea model setup $(0.25 \mathrm{nmi}, \sim 460 \mathrm{~m})$ enables simulations of the effects of the dense archipelago and complex geometry on the transport of substances through the area. However, it is still not sufficient to solve all the details of the inner archipelago. This limitation might affect the accuracy of our simulations, especially in narrow channels and in areas where there are dense clusters of islands. For example, the channels leading to the middle archipelago are only less than $1-\mathrm{km}$ wide at their narrowest points, and at the entrance of the western channel, there are islands with $300-\mathrm{m}$ diameter that cannot be described properly with the current resolution. Current computational resources limit the use of a higher resolution except for in small limited areas. In the future, unstructured grid models might provide a solution for modelling this type of areas. However, making a representative grid for such a fractal area would require extensive effort.

The accuracy and resolution of the wind forcing is also an important factor in the simulation of currents. The forcing used in this study is from FMI's numerical weather prediction system HIRLAM, which had changes in both physics and parameterisations and horizontal and vertical resolution during our simulation period of 2009-2015. Even the highest horizontal resolution of the forcing, $7.5 \mathrm{~km}$, which was used for the years 2012-2015, is relatively coarse for the archipelago area. However, previous studies have shown that using meteorological forcing with a finer resolution of $2.5 \mathrm{~km}$ does not significantly affect the modelled circulation in the Archipelago Sea (Tuomi et al. 2018).
In the 3-month particle simulations (Section 4), we selected three points in the outer archipelago to represent transport coming to the Archipelago Sea from the Bothnian Sea ("N"), the Baltic Proper ("S") and the Gulf of Finland ("SE"). We ran several simulations with different point sources and these three locations were selected based on the openness of the archipelago and the south-north aligned channels, which play the key part in the transport of substances through the archipelago. As the southern part of the model domain has a longer open boundary and larger number of channels than the northern part, we choose two different locations to ensure the representativeness of particle transport from this area.

When running the particle drift simulations, we used simulation periods of 3 months. This choice was due to practical reasons to keep the number of particles and the simulation running times reasonable with the computational resources available. The start of the simulation period was chosen to be January to represent the thermal seasons of this area. January-March is typically the period when there is ice cover in the Archipelago Sea. April-June is the spring season, when the ice melts away and the surface layer starts to form. JulySeptember represents the summer season, with strong vertical stratification in the deep areas of the Archipelago Sea. October-December represents the autumn with cooling and mixing of the surface layer. Although this selection is justified, longer simulation periods might better represent the variability in the system and the behaviour during extreme wind events. In the future, the availability of better computational resources would enable the use of longer simulation periods and larger amounts of particles.

\section{Conclusions}

We studied water age and transports in the Archipelago Sea using the COHERENS 3D hydrodynamic model and the OpenDrift Lagrangian particle model. Based on the results of 6-year (2010-2015) model hindcasts, the mean water age varied from less than 3 months in the outer archipelago to up to 7 months in the inner archipelago. The lowest values occurred in the river mouths and in the open boundary areas of the outer archipelago. The water age in the bottom layer was very similar to that in the surface layer: significant differences were seen only in the river mouths and in the deep channels of the middle archipelago. The mean water age was generally lower during autumn and winter seasons than during the summer season due to the seasonal variations in the current speeds.

The analysis of annual mean values of water age revealed significant inter-annual variability in the system due to the inter-annual variation in wind conditions. The largest differences were seen in 2010 and 2015. In 2010, the water age was 
up to 1 month lower in the south-western part of the Archipelago Sea and higher in the north-western part compared with the mean over the whole simulation period. In 2015 , the situation was the opposite of that in 2010. The other years fell in between these two opposite modes.

The transport of particles from the outer archipelago to the middle and inner archipelago is very sensitive to the geometry and density of islands in the area. The prevailing wind direction, SW, is not optimal for the transport of large amounts of particles to the middle archipelago. The NW winds induced most transport from the northern boundary to the middle archipelago. From the southern boundary, transport was seen mainly with the prevailing winds from between ESE and SSW but also with combinations of SW and SE winds. The transport from open sea areas to the inner archipelago was limited to only few cases, and these areas are relatively sheltered from transport from the outer and middle archipelagos.

Both the water age simulation and the particle transport simulations showed that the Archipelago Sea is a very dynamic area. The outer archipelago has constant water exchange with the Bothnian Sea and the Baltic Proper. The middle archipelago is relatively sheltered and the water exchange with the outer archipelago is dependent on high wind events from the NW and SE directions. The inner archipelago is mostly sheltered and is under major influence from local riverine inputs. This indicates that the eutrophied parts of the inner archipelago are mostly affected by local sources only.

Acknowledgements We thank Janne Ropponen for the code for calculating water age in the COHERENS version 2.9.

For Fig. 1, the shapefile containing the water bodies in the Archipelago Sea, delineated in the EU Water Framework Directive (2000/60/EY, 23.10.2000), was obtained from the open data service of Finnish Environment Institute (SYKE, https://www.syke.fi/en-US/Open information/Spatial_datasets/). It has been produced by SYKE and Centers for Economic Development, Transport and the Environment (ELY Centers) and licensed under the Creative Commons Attribution 4. 0 International license (CC BY 4.0, https://creativecommons.org/ licenses/by/4.0/).

For the Baltic model setup, sea-level data for the open sea boundary at Kattegat were obtained from the SMHI open data service (http:// opendata-download-ocobs.smhi.se/explore/), licensed under the Creative Commons BY-2.5 license (CC BY 2.5, https:// creativecommons.org/licenses/by/2.5/). Salinity and temperature profiles for the open sea boundary at Kattegat were produced using information from the EU's Copernicus Marine Service (http://marine.copernicus.eu/).

Funding Open access funding provided by Finnish Environment Institute (SYKE). This work has been supported by the Finnish Ministry of Environment (RaKi Nutrient Cycling project, project number 7020P-00696YMP01), the Strategic Research Council at the Academy of Finland (contract number 312650, BlueAdapt) and the European Maritime and Fisheries Fund (Vesiviljelyn innovaatio-ohjelma).

Open Access This article is licensed under a Creative Commons Attribution 4.0 International License, which permits use, sharing, adaptation, distribution and reproduction in any medium or format, as long as you give appropriate credit to the original author(s) and the source, provide a link to the Creative Commons licence, and indicate if changes were made. The images or other third party material in this article are included in the article's Creative Commons licence, unless indicated otherwise in a credit line to the material. If material is not included in the article's Creative Commons licence and your intended use is not permitted by statutory regulation or exceeds the permitted use, you will need to obtain permission directly from the copyright holder. To view a copy of this licence, visit http://creativecommons.org/licenses/by/4.0/.

\section{References}

Andrejev O, Myrberg K, Lundberg PA (2004) Age and renewal time of water masses in a semi-enclosed basin - application to the Gulf of Finland. Tellus A 56(5):548-558

Andrejev O, Soomere T, Sokolov A, Myrberg K (2011) The role of the spatial resolution of a three-dimensional hydrodynamic model for marine transport risk assessment. Oceanologia 53(1-TI):309334. https://doi.org/10.5697/oc.53-1-TI.309

Bergström S, Carlsson B (1994) River run-off to the Baltic Sea: 19501990. Ambio 23:280-287

Bolin B, Rodhe H (1973) A note on the concepts of age distribution and transit time in natural reservoirs. Tellus 25(1):58-62

Braunschweig F, Martins F, Chambel P, Neves R (2003) A methodology to estimate renewal time scales in estuaries: the Tagus Estuary case. Ocean Dyn 53:137-145. https://doi.org/10.1007/s10236-003-00400

Dagestad KF, Röhrs J (2019) Prediction of ocean surface trajectories using satellite derived vs. modeled ocean currents. Remote Sens Environ 223:130-142. https://doi.org/10.1016/j.rse.2019.01.001

Dagestad KF, Röhrs J, Breivik Ø, Ådlandsvik B (2018) OpenDrift v1.0: a generic framework for trajectory modelling. Geosci Model Dev 11: 1405-1420. https://doi.org/10.5194/gmd-11-1405-2018

Deleersnijder E, Campin JM, Delhez EJM (2001) The concept of age in marine modelling: 1 . Theory and preliminary model results. J Mar Syst 28(3-4):229-267. https://doi.org/10.1016/S0924-7963(01) 00026-4

Delhez EJM, Campin JM, Hirst AC, Deleersnijder E (1999) Toward a general theory of the age in ocean modelling. Ocean Model 1:1727. https://doi.org/10.1016/S1463-5003(99)00003-7

Döös K, Meier HEM, Döscher R (2004) The Baltic haline conveyor belt or the overturning circulation and mixing in the Baltic. AMBIO 33(4):261-266. https://doi.org/10.1579/0044-7447-33.4. 261

Engqvist A, Döös K, Andrejev O (2006) Modeling water exchange and contaminant transport through a Baltic coastal region. AMBIO 35(8):435-447. https://doi.org/10.1579/0044-7447(2006)35[435: MWEACT]2.0.CO;2

Gutow L, Ricker M, Holstein J, Dannheim J, Stanev E, Wolff JO (2018) Distribution and trajectories of floating and benthic marine macrolitter in the south-eastern North Sea. Mar Pollut Bull 131: 763-772. https://doi.org/10.1016/j.marpolbul.2018.05.003

HIRLAM-B (2016) System documentation. http://hirlam.org/

Huttunen I, Huttunen M, Piirainen V, Korppoo M, Lepistö A, Räike A, Tattari S, Vehviläinen B (2016) A national-scale nutrient loading model for Finnish watersheds - VEMALA. Environ Model Assess 21:83-109. https://doi.org/10.1007/s10666-015-9470-6

Jones CE, Dagestad KF, Breivik Ø, Holt B, Röhrs J, Christensen KH, Espeseth M, Brekke C, Skrunes S (2016) Measurement and modeling of oil slick transport. J Geophys Res Oceans 121:77597775. https://doi.org/10.1002/2016JC012113

Jönsson B, Lundberg PA, Döös K (2004) Baltic sub-basin turnover times examined using the Rossby Centre Ocean Model. AMBIO 33(4): 257-260. https://doi.org/10.1579/0044-7447-33.4.257 
Kanarik H, Tuomi L, Alenius P, Lensu M, Miettunen E, Hietala R (2018) Evaluating strong currents at a fairway in the Finnish Archipelago Sea. J Marine Sci Eng 6:122. https://doi.org/10.3390/jmse6040122

Kvile KØ, Romagnoni G, Dagestad KF, Langangen Ø, Kristiansen T (2018) Sensitivity of modelled North Sea cod larvae transport to vertical behaviour, ocean model resolution and interannual variation in ocean dynamics. ICES J Mar Sci 75:2413-2424. https://doi.org/ 10.1093/icesjms/fsy039

Lignell R, Miettunen E, Tuomi L, Ropponen J, Kuosa H, Attila J, Puttonen I, Lukkari K, Peltonen H, Lehtoranta J, Huttunen M, Korppoo M, Tikka K, Mäyrä J, Heiskanen AS, Gustafsson B, Gustafsson E, Hänninen J, Thingstad F, Kaurila K, Vanhatalo J, Westerlund A, Siiriä SM (2018) Rannikon kokonaiskuormitusmalli: ravinnepäästöjen vaikutus veden tilaan - Kehityshankkeen loppuraportti (XI 2015 - VI 2018). https://www.ym.fi/download/ noname/\%7BD5C68F2D-D52B-4C73-9E0B-FE53C5FFD207\% 7D/142893 (In Finnish). Accessed 19 Sept 2019

Luyten P (Editor) (2013) COHERENS - a coupled hydrodynamicalecological model for regional and shelf seas: user documentation. Version 2.5.1. RBINS-MUMM Report, Royal Belgian Institute of Natural Sciences

Meier HEM (2005) Modeling the age of Baltic seawater masses: quantification and steady state sensitivity experiments. J Geophys Res Oceans 110, C02006. https://doi.org/10.1029/2004JC002607

Meier HEM (2007) Modeling the pathways and ages of inflowing saltand freshwater in the Baltic Sea. Estuar Coast Shelf Sci 74:610 627, https://doi.org/10.1016/j.ecss.2007.05.019

Mouchet A, Cornaton F, Deleersnijder E, Delhez ÉJ (2016) Partial ages: diagnosing transport processes by means of multiple clocks. Ocean Dyn 66(3):367-386. https://doi.org/10.1007/s10236-016-0922-6

Myrberg K, Andrejev O (2006) Modelling of the circulation, water exchange and water age properties of the Gulf of Bothnia. Oceanologia 48(S):55-74

Seifert T, Tauber F, Kayser B (2001) A high resolution spherical grid topography of the Baltic Sea - 2nd edition. Baltic Sea Science Congress, Stockholm 25-29. November 2001, Poster 147
Siddorn JR, Furner R (2013) An analytical stretching function that combines the best attributes of geopotential and terrain-following vertical coordinates. Ocean Modelling 66:1-13. https://doi.org/10.1016/ j.ocemod.2013.02.001

Smagorinsky J (1963) General circulation experiments with the primitive equations - I. The basic experiment. Mon Weather Rev 91:99-164

Sokolov A, Andrejev O, Wulff F, Rodriguez Medina M (1997) The data assimilation system for data analysis in the Baltic Sea. Systems Ecology Contributions, 3, Stockholm University, 1997, 66pp.

Stanev EV, Badewien TH, Freund H, Grayek S, Hahner F, Meyerjürgens J, Ricker M, Schöneich-Argent R, Wolff JO, Zielinski O (2019) Extreme westward surface drift in the North Sea: public reports of stranded drifters and Lagrangian tracking. Cont Shelf Res 177:24 32. https://doi.org/10.1016/j.csr.2019.03.003

Suominen T, Tolvanen H, Kalliola R (2010) Surface layer salinity gradients and flow patterns in the archipelago coast of SW Finland, northern Baltic Sea. Mar Environ Res 69(4):216-226. https://doi. org/10.1016/j.marenvres.2009.10.009

Tuomi L, Miettunen E, Alenius P, Myrberg K (2018) Evaluating hydrography, circulation and transports in a coastal archipelago using a high-resolution $3 \mathrm{~d}$ hydrodynamic model. J Mar Syst 180:2436. https://doi.org/10.1016/j.jmarsys.2017.12.006

van Sebille E, Griffies S, Abernathey R, Adams T, Berloff P, Biastoch A, Blanke B, Chassignet E, Cheng Y, Cotter C, Deleersnijder E, Döös K, Drake H, Drijfhout S, Gary S, Heemink A, Kjellsson J, Koszalka I, Lange M, Lique C, MacGilchrist G, Marsh R, Mayorga Adame CG, McAdam R, Nencioli F, Paris C, Piggott M, Polton J, Rühs S, Shah S, Thomas M, Wang J, Wolfram P, Zanna L, Zika J (2018) Lagrangian ocean analysis: Fundamentals and practices. Ocean Model 121:49-75. https://doi.org/10.1016/j.ocemod.2017.11.008

Viikmäe B, Soomere T (2018) The persistence of spatial patterns of beaching of current-driven pollution in a changing wind climate: a case study for the Gulf of Finland. Boreal Environ Res 23:299-314 